Portland State University

PDXScholar

\title{
A Description and Evaluation of the Self-Help Information Service
}

\author{
Cathy Tuma \\ Portland State University \\ John Wadsworth \\ Portland State University
}

Follow this and additional works at: https://pdxscholar.library.pdx.edu/open_access_etds

Part of the Mental and Social Health Commons, and the Social Work Commons Let us know how access to this document benefits you.

\section{Recommended Citation}

Tuma, Cathy and Wadsworth, John, "A Description and Evaluation of the Self-Help Information Service" (1981). Dissertations and Theses. Paper 3460.

https://doi.org/10.15760/etd.5344

This Thesis is brought to you for free and open access. It has been accepted for inclusion in Dissertations and Theses by an authorized administrator of PDXScholar. Please contact us if we can make this document more accessible: pdxscholar@pdx.edu. 
A DESCRIPTION AND EVALUATION OF THE

SELF-HELP INFORMATION SERVICE ${ }^{1}$

\author{
by \\ Cathy Tuma \\ and
}

John Wadsworth

\author{
Research practicum in partial fulfillment \\ of the requirements for the degree of \\ Master of Social Work
}

Portland State University

1981

$1_{\text {This }}$ research practicum was partially supported by National Institute of Mental Health Grant RO 1 MH 33716-02. 
TO THE OFFICE OF GRADUATE STUDIES:

The research practicum is approved as presented herein June 5, 1981 .

APPROVED:

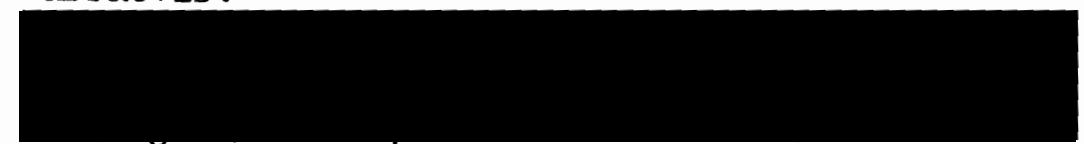

June Dunn, M.S.W., P.S.U. School of Social Work

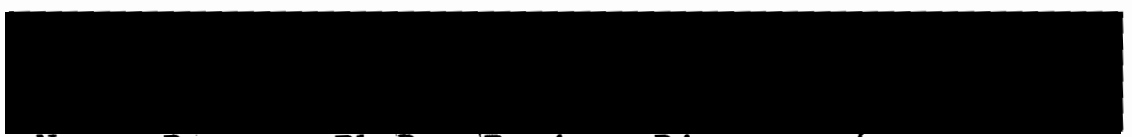

Nancy Barron, Ph.D., Project Director

Self-Help Project 


\section{ACKNOWLEDGEMENTS}

Without the cooperation and assistance of many people, this research practicum would not have been possible. The authors extend their sincere gratitude to the staffs of the Self-Help Project, the Regional Research Institute, and Tri-County Information and Referral. Our faculty advisor, June Dunn, MSW, has been both patient and supportive of our efforts. Margaret LaFaive has generously supplied her time and expertise in the editing and typing of this manuscript. Very special thanks are due to Nancy Barron, Ph.D. Her support and assistance have been instrumental in the completion of this research practicum. Finally, we wish to acknowledge our appreciation of the cooperation and support generously provided by the members of the self-help groups we contacted and the users of SIS who consented to share their experience and opinions with us. 


\section{ABSTRACT}

The purpose of this study was to evaluate the effectiveness of the Self-Help Information Service (SIS) and to obtain information necessary for the improvement of the service. The study also described the development and operation of SIS and assessed the use and effect of the service. The evaluation of SIS was based on initial global utilization data and the results of participant satisfaction surveys targeted at four distinct groups: (1) Self-Help Project staff, (2) Tri-County Information and Referral Service staff, (3) self-help groups, and (4) callers of the service (potential members of self-help groups). The Self-Help Project and $\operatorname{Tr} i-C o u n t y ~ I \& R$ staffs represent staff samples; the self-help groups and potential members represent consumer samples. An ex-post facto design was utilized as single measurements, using questionnaires, were taken of the four sample groups after contact with the service. The findings were interpreted by comparing present conditions of the respondents to conditions when the service began in December, 1980; by how well the service has met Project staff expectations; and by comparing SIS to other Self-Help Information and Referral services around the country.

of the consumers of the service surveyed, the self-help groups were satisfied with their contact with SIS, and the callers indicated they were satisfied with the service they had received. The Self-Help Project staff and the $I \& R$ staff both indicated satisfaction with the overall performance of SIS and agreed SIS was effective in reaching the stated goals of the service. 
Three other Self-Help Information and Referral services were located in the United States, all in New York state. Comparison of SIS to these services indicated that although SIS developed independently of the New York services, many similarities and no major differences were evidenced among the organizations.

Recommendations of the consumers of SIS focused on the need for greater publicity to let the community know of the existence of the service. Recommendations of the staffs focused on the need for systematic, written procedures for processing contacts with potential group members. The staff of the Self-Help Project frequently suggested that Project staff devise a training program to orient $I \& R$ staff to specific procedures used for the operation of SIS as well as to provide an overview of the system.

The Self-Help Information Service was a fledgling service at the time of the evaluation, having been in existence for only two months. The consumer and staff recommendations will be used to modify SIS to improve the delivery of service to the community. 
TABLE OF CONTENTS

ACKNOWLEDGEMENTS . . . . . . . . . . . . . . . . . . . . iii ABSTRACT . . . . . . . . . . . . . . . . . . . . . . iv LIST OF TABLES . . . . . . . . . . . . . . . . . . . . . . ix LIST OF FIGURES • • . . . . . . . . . . . . . . . . . . . . . . xiv CHAPTER

I INTRODUCTION . . . . . . . . . . . . . . . . . 1

The Study . . . . . . . . . . . . . . . . 1

The Self-Help Project and SIS . . . . . . . . . 2

II DEFINITION OF A SELF-HELP GROLP . . . . . . . . . . . . . 5

III LITERATURE REVIEW •. . . . . . . . . . . . . . . 7

Historical Perspective on the Development of

Self-Help Ideology . . . . . . . . . . . . . 7

Self-Help in America: $1930^{\prime}$ s to the Present . . . . . 9

Self-Help Groups and the Chronically Mentally I11 • . 11

Definition of the Chronically Mentally III . . . . . 12

Self-Help and the Mentally Ill . . . . . . . . . 13

Self-Help Groups for Parents and Friends of the

Chronically Mentally Ill . . . . . . . . . 16

Professional Collaboration With Self-Help Groups

for the Mentally Ill . . . . . . . . . . 18

IV PROGRAM DESCRIPTION . . . . . . . . . . . . . . 21

Mission and Goals of SIS . . . . . . . . . . . 21

Needs Assessment . . . . . . . . . . . . . . 21 
Resource Inventory . . . . . . . . . . . . . . 22

Potential Member Inventory . . . . . . . . . . 24

Information Campaign . . . . . . . . . . . . 25

Collaboration With Tri-County Information and

Referral .................... 26

V RESEARCH DESIGN AND METHODOLOGY . . . . . . . . . . . 28

Participants in the Study . . . . . . . . . . 28

Method of Study . . . . . . . . . . . . . 29

Data Collection . . . . . . . . . . . . 31

Data Analysis . . . . . . . . . . . . . 32

VI RESULTS . . . . . . . . . . . . . . . . . . 33

Self-Help Project Staff Questionnaire . . . . . . . 33

Findings . . . . . . . . . . . . . . . 34

Summary . . . . . . . . . . . . . . 38

I \& R Staff Questionnaire . . . . . . . . . . 38

Utilization Data . . . . . . . . . . . . . . 38

Sample . . . . . . . . . . . . . . . 39

Findings . . . . . . . . . . . . . . . 40

Summary . . . . . . . . . . . . . . . 43

Self-Help Group Questionnaire . . . . . . . . . 43

Findings . . . . . . . . . . . . . . 43

Summary . . . . . . . . . . . . . . 45

Caller Questionnaire . . . . . . . . . . . 45

Sample . . . . . . . . . . . . . . 45

Findings . . . . . . . . . . . . . . . . 46

Sumary . . . . . . . . . . . . . . . 50 
VII SUMMARY, RECOMMENDATIONS AND DISCUSSION : . . , . . . 51

Sumary of Findings . . . . . . . . . . . . . . . 51

Recommendations ................. . 53

Discussion . . . . . . . . . . . . . . 53

APPENDIX A . . . . . . . . . . . . . . . . . . . . 56

APPENDIX B . . . . . . . . . . . . . . . . . . . . . 63

APPENDIX C . . . . . . . . . . . . . . . . . . . 65

APPENDIX D . . . . . . . . . . . . . . 67

APPENDIX E . . . . . . . . . . . . . . . . . . . . 69

APPENDIX F . . . . . . . . . . . . . . . . . . . . . 70

APPENDIX G . . . . . . . . . . . . . . . . . . . . 71

APPENDIX H . . . . . . . . . . . . . . . . . 88

APPENDIX I . . . . . . . . . . . . . . . . . . 99

APPENDIX J . . . . . . . . . . . . . . . . . . . 102

APPENDIX K . . . . . . . . . . . . . . . . . . . 119

APPENDIX L . . . . . . . . . . . . . . . . 124

APPENDIX M . . . . . . . . . . . . . . . . . . . . 129

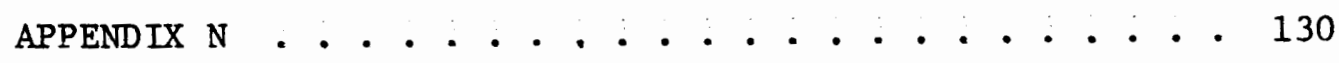

BIBLIOGRAPHY • . . . . . . . . . . . . . . . 135 


\section{LIST OF TABLES}

TABLE

TABLE

TABLE

TABLE

TABLE

TABLE

TABLE

TABLE

TABLE

TABLE

TABLE

TABLE

TABLE

TABLE

TABLE
I Staff Time Working on the Group Inventory . . .

II Staff Satisfaction With Time Spent on the

$$
\text { Group Inventory . . . . . . . . . . }
$$

III Usefulness of the Inventory Form . . . . . . 73

IV Staff Opinion of Group Inventory Procedures . . . 74

V Clarity of Group Inventory Directions . . . . . . 74

VI Staff Comfort Contacting Groups . . . . . . . 75

VII Staff Time Working on Potential Member

Inventory . . . . . . . . . . . 76

VIII Staff Satisfaction With Time Spent on Potential

Member Inventory . . . . . . . . . 76

IX Usefulness of the Potential Member

Questionnaire .. . . . . . . . . 77

X Staff Opinion of Potential Member Inventory

Procedures . . . . . . . . . . . 77

XI Clarity of Potential Member Inventory

Directions . . . . . . . . . . . 78

XII Staff Comfort Contacting Potential Members . • 78

XII Staff Time Working on the Information Campaign . 79

XIV Staff Satisfaction With Time Spent on the

Information Campaign . . . . . . . . 79

XV Usefulness of Poster in Conveying Necessary

Information . . . . . . . . . . . . . 
TABLE

XVI Staff Opinion of Information Campaign

Procedures . . . . . . . . . . . . . 80

TABLE

$$
\text { XVII }
$$

Clarity of Directions for Information Campaign .

TABLE

$$
\text { XVIII }
$$$$
\text { Staff Comfort Disseminating SIS Information ... }
$$

TABLE

$$
\mathrm{XIX}
$$$$
\text { Satisfaction With Referral Procedures . . . . . }
$$

TABLE XX

$$
\text { Stafe }
$$

$$
\mathrm{XXI}
$$

Staff Satisfaction With Time Spent at Tri-County

$I \& R$. . . . . . . . . . . . . . . .

TABLE

$$
\text { XXII }
$$

Staff Satisfaction With I \& R Training

TABLE

XXIII

Attitudes of

TABLE

XXIV.

Attitudes

$\mathrm{XXV}$

Overall Staff Satisfaction With SIS . . . . .

TABLE

XXVI

Student Opinion of Involvement With SIS . . . .

TABLE

XXVII

Research Assistant Opinion of Involvement

With SIS... . . . . . . . . . .

TABLE XXVIII Procedures when a Group is Available for

Referral . . . . . . . . . . . .

TABLE

XIX

Procedures When a Group is not Available for

Referral ..................

TABLE

$\mathrm{XXX}$

Worker Training to Use Potential Member Forms .

TABLE XXXI Workers Comfortable Responding to Potential

Member Requests for Further Information .. 90

TABLE XXXII How Potential Member Procedures Affect On-Line

Functioning . . . . . . . . . . . . 90

\section{TABLE XXXIII}

Procedures for Use of the Group Inventory Form . 
$\mathbf{x i}$

TABLE XXXV Workers Comfortable Responding to Self-Help Group Requests for Further Information . . . . . 92

TABLE XXXVI How Group Inventory Procedures Affect On-Iine

Functioning . . . . . . . . . . . 92

TABLE XXXVII How Often Referrals are Made Promptly when a

Group is Available . . . . . . . . . 93

TABLE XXXVIII How Often Referrals Made are Appropriate . . . 93

TABLE XXXIX Satisfaction With SIS Referral Procedures Used

by Self-Help Project Staff . . . . . . 94

TABLE XL Workers Having Knowledge of Written $I \& R$

Procedures Incorporating SIS into I \& R . . . 94

TABLE XII Workers Having a Picture of the Total System

of SIS................... 95

TABLE XII Orientation Needed to Give a View of the Total

System ................. 95

TABLE XLIII Impact of SIS on Day-to-Day On-Line Functioning • 96

TABLE XIV Satisfaction With Collaboration Between SIS

and $I \& R$. . . . . . . . . . . 96

TABLE XLV Attitudes of SIS Staff Toward the I \& $R$ Worker.

TABLE XIVI Extent SIS Reached Goal of Expanding I \& $R$

Resources . . . . . . . . . . 97

TABLE XLVII Effectiveness of SIS in Reaching Overall Goals . 97

TABLE XIVIII Impact of SIS on I \& R Service . . . . . . . . 98

TABLE XLIX SIS Contacted by Self-Help Group . . . . . . . 99

TABLE I Helpfulness of SIS Registration to Self-Help Group .................. 100 
TABLE II Self-Help Group Satisfaction With SIS Contact . 100

TABLE LII Self-Help Group Suggestions for Improving SIS . . 101

TABLE LIII Contact with Tri-County I\& R : . . . . . . 102

TABLE LIV Friendly and Helpful I\& R Staff . . . . . . . 102

TABLE LV Contact with PSU . . . . . . . . . . . . 103

TABLE LVI Friendly and Helpful PSU Staff . . . . . . . 103

TABLE IVII I \& R Referral to PSU or PSU Referral to I\& R . 103

TABLE LVIII Consistent Information Given by I \& R and PSU - . 104

TABLE LIX Difficulty Contacting SIS . . . . . . . . . 105

TABLE LX Difficulties Encountered in Contacting SIS . • 105

TABLE LXI Respondents' Feelings About Calling SIS . . . . 105

TABLE IXII Callers Asking for Membership . . . . . . . 105

TABLE LXIII Callers Asking for Information Other Than

Membership ................ 106

TABLE LXIV Caller Satisfaction With Responses From SIS . • 106

TABLE LXV Callers Referred to a Group . . . . . . . . . 107

TABLE LXVI Groups Referred . . . . . . . . . . . 107

TABLE LXVII Difficulties in Contacting a Group Represen-

tative................ 107

TABLE LXVIII Attendance at Group Meetings . . . . . . . . 108

TABLE LXIX Number of Meetings Attended . . . . . . . . 108

TABLE IXX Reasons for Non-Attendance . . . . . . . . 109

TABLE IXXI Referrals Appropriate . . . . . . . . 109

TABLE IXXII Group Members' Concerns Similar to Respondents'

Concerns ............... 109

TABLE LXXIII Continuing Attendance at Group Meetings . . . . 110 
TABLE LXXIV Reasons for Terminating Attendance at Group . . . 110

TABLE LXXV Concerns/Needs Met by Group . . . . . . . . . . 111

TABLE LXXVI Plans to Continue Attending Group Meetings • • 111

TABLE LXXVII Impact of Group on Callers Feelings About Their Concerns ............... 112

TABLE LXXVIII Requested by Staff to be on a Waiting List . . 112

TABLE LXXIX Agreed to be on a Waiting List . . . . . . . 112

TABLE LXXX Satisfaction With Placenent on Waiting List When

No Group Available . . . . . . . . . 113

TABLE IXXXI Told SIS Staff Would Re-Contact........ 113

TABLE LXXXII SIS Staff Did Re-Contact . . . . . . . . . 114

TABLE LXXXIII SIS Staff Friendly and Helpful . . . . . . . . 114

TABLE LXXXIV Agreed to Help Form a Group . . . . . . . . . . . 114

TABLE LXXXV Have Had Opportunity to Help Form a Group . . , 115

TABLE LXXXVI Helpfulness of Procedures for Forming a Group . . 115

TABLE LXXXVII SIS Provided Accurate Information . . . . . . 116

TABLE LXXXVIII Willing to Refer a Friend or Relative to SIS • 116

TABLE LXXXIX Overall Satisfaction With SIS . . . . . . . 117

TABLE XC Reasons for Satisfaction/Dissatisfaction . . . 117

TABLE XCI Further Comments About SIS . . . . . . . . . 118 


\section{LIST OF FIGURES}

FIGURE I Impact of SIS on Number of Calls to I \& $R$ Asking for Self-Help Information ............ 39 FIGURE 2 How Respondents Funnel Down Through the Referral Process . . . . . . . . . . . . . 48 
CHAPTER I

INTRODUCTION

THE STUDY

This study is focused on a Self-Help Information and Referral System (SIS) for the greater Portland area. The aims of SIS are threefold: (1) to broaden the base of the Tri-County Information and Referral Service to include an accurate inventory of the number and scope of Portland area self-help groups, (2) to facilitate the linkage of community members interested in self-help groups with self-help groups capable of meeting their interests and/or concerns, and (3) to obtain accurate information about the number of individuals in the commuity interested in utilizing self-help groups and the scope of their concerns or interests. An additional aim of this study is to review the literature about self-help groups and to assess the potential of self-help groups in meeting the needs of the chronically mentally ill.

The purpose of this study is to evaluate the effectiveness of SIS and thus obtain information necessary for the improvement of SIS (i.e. a formative administrative evaluation for program improvement) (NIMH, 1979). In addition, this study serves the purpose of documenting the Self-Help Project's approach towards the development and operation of a self-help information and referral service for other interested projects. The study is descriptive, Involving a review of the literature and an account of the development and operation of SIS. The study is also evaluative, 
involving an assessment of the use and effect of SIS. The evaluation of SIS includes the results of participant satisfaction surveys targeted at four distinct groups: (1) self-help groups, (2) potential members of self-help groups, (3) the staff of the Tri-County Information and Referral Service, and (4) the staff of the Self-Help Project. Representatives of self-help groups and potential self-help group members were interviewed by telephone. The staff of both Tri-County Information and Referral Service and the Self-Help Project were interviewed face-to-face.

\section{THE SELF-HELP PROJECT AND SIS}

The Self-Help Project, a federally funded research project, was awarded a three-year contract by the National Institute of Mental Health to assess the potential which self-help groups hold for the delivery of human services in an urban setting. The Self-Help Project as a whole is focused on several areas relevant to this goal: (1) the scope of problems addressed by urban self-help groups, (2) a comparison of the different processes used by self-help groups and professional helpers, (3) the efficacy of self-help groups in dealing with mental health related problems, and (4) the enhancement of self-help group efficacy through professional-group interaction.

As an integral facet in its study of self-help groups, the SelfHelp Project has developed SIS in conjunction with the Tri-County Information and Referral Service in Portland. By inventorying self-help groups and advertising the information and referral service to link potential members with groups, SIS benefits the Tri-County Information and Referral Service by enhancing the scope and quality of their service. Furthermore, SIS facilitates the research project in a number of ways. 
As noted in the 1iterature (Harris, 1966; Silverman, 1978; Tracy \& Gussow, 1976), professionals researching self-help groups often experience difficulties in their relations with the groups. However, positive, collaborative relationships between professionals and self-help groups have been facilitated when two conditions are met: (1) the professional provides a useful service to the group and (2) professional-group interactions are not based solely on the research goals of the professional (Lieberman \& Borman, 1976). The development of a common ground between the professional and the self-help group is facilitated by a relationship involving mutual benefit. Thus, while providing a valuable commity service, SIS also facilitates a positive working relationship between the Self-Help Project and Tri-County area self-help groups--an essential ingredient for effective research (Bakker \& Karel, 1970a; Bumbalo and Young, 1973; Dumont, 1974).

The completion of a self-help group resource inventory has provided an estimate of both the number and scope of self-help groups in the tri-county area. In addition, the inventory furnishes the logistical framework necessary for referrals of community members to self-help groups. A comparison of the results of the community needs assessment and the availability of the self-help groups comprising the resource inventory will provide the basis for generating particular types of self-help groups directed at meeting specific unmet community needs. SIS users with a common concern for which there is presently no self-help group available provide a waiting list of persons interested in participating in particular types of self-help groups. This waiting list pool is then tapped as the Self-Help Project generates new self-help groups 
to meet the users concerns. Thus, SIS is both a service to the community and an integral and necessary component of the project's overall research goals. 
CHAPTER II

DEFINITION OF A SELF-HELP GROUP

First needed, before a discussion of the literature review, is a working definition of a self-help group. Drawing heavily upon Levy's definitions (1976, pp. 311-313), the Self-Help Project devised the following definition of a self-help group: A mutual aid/self-help group is an interacting face-to-face group whose domain of interest is the physical or mental health or social well-being of its members, which controls itself, whose members experience a sense of group identity related to their experiences and concerns and whose members exchange peer helping as the primary source of help.

Defining characteristics of a mutual aid/self-help group include:

1. The group is a face-to-face interacting group.

2. The group is the source of power over itself. Control of the group and authority or sanction for it come from within-the group owns the group.

3. The group members experience a sense of group identity (community). Group membership is based on common experience. The group's concern matches a major area of group members' common experience.

4. Members believe that their peers, especially other group members, are a primary resource for their health and well-being.

5. Members exchange helping in the form of affection, respect, information, (generally not services, usually not goods or money). A norm of reciprocity exists within the group (although this may be spread over time). 
Characteristics which distinguish among mutual aid/self-help groups include: concern, composition, group function, group structure, group interaction, professional involvement and the relationships of a group to other societal organizations.

Two key questions to apply to self-help groups are: Does the group control itself? Would the group exist if any professional/ bureaucratic support were withdrawn? 
CHAPTER III

\section{LITERATURE REVIEW}

A computer search of four data bases, NCMM, ERIC, SSCI, and PSYCM was conducted on self-help, and self-help and the chronically mentally 111. In addition, key informants in the area of self-help were solicited for further contributions (for a summary of their responses see Appendix A). The results of these efforts were reviewed and incorporated into a review of the literature about self or mutual-help and a description of the state of the art regarding self-help and the chronically mentally 111.

HISTORICAL PERSPECTIVE ON THE DEVELOPMENT OF SELF-HELP IDEOLOGY

The practice of mutual aid reaches far back into the history of humankind. The basis of civilization lies in early cooperation and mutual aid practices such as food-gathering and group safety and defense. According to Kropotkin (1973, pp. 85-96\& 109-110), tribal or clan societies survived due to cooperative efforts; the stronger clans gradually formed a new type of social organization--the village community. The Middle Ages brought the expansion of mutual aid beyond mere physical survival, but aid was extended only to those of the guild or the comunity. (Kropotkin, 1972, pp. 184-221).

Centuries later, the Friendly Societies were developed by working people in England to cope with the stresses of the Industrial Revolution. The Friendly Societies often centered around occupational groups and 
gradually evolved into Trade Clubs and then into Trade Unions aimed at improving the living and working conditions of the members. Thompson (1963, p. 422) says the eighteenth century Friendly Societies and organizations emphasized Christian charity, the social being of the human and the continual need for mutual assistance and support. Guilds, Friendly Societies, and unions appear to have been the main mutual-aid organizations of the late eighteenth and early nineteenth centuries in England. Lieberman and Borman (1976, p. 457) believe that modern selfhelp groups may be stimulated by processes not unlike those that brought about the Friendly Societies and labor unions in eighteenth century England.

Katz and Bender (1976, p. 275) point out that during the nineteenth century massive waves of immigration to the United States, composed mainly of people from peasant backgrounds, brought many adjustment problems for immigrants and their families. "The Melting Pot was in reality a cauldron of resentments among immigrant ethnic groups, on the one hand, and between them and the earlier, more assimilated Anglo-Saxon immigrants on the other." (Katz \& Bender, 1976, p. 275). Lacking outside supports, recent immigrants turned to each other for help with the pressures and problems of daily living soon after arrival in the "land of opportunity."

Ethnic groups set up their own mutual aid societies, sometimes known as "Landsmanschaften" meaning that relatives and neighbors who had immigrated from the same region or town could join them. For example, the Greek communities carried out mutual aid through the Pan-Hellenic Union which dispensed sickness and death benefits, the Polish National Alliance serviced the Slavic population providing such services as temporary lodging for Poles just "coming off the boat" and having a 
youth membership. However, after immigration to North America had slowed to a trickle and the immigrants had assimilated into the established culture, the self-help and mutual-aid organizations, including the Landsmanschaften, slowly declined and disappeared. (Katz \& Bender, 1976).

Self-Help in America: $1930^{\prime}$ 's to the Present

According to Hurvitz (1976, pp. 283-294), self-help programs developed in response to the problems of the Great Depression. Increasing numbers of Americans needed inexpensive yet effective psychiatric and psychological services. However, the existing system of psychodynamic psychotherapy was unable to meet that need and new methods and practices of psychotherapy were necessary (Brenner, 1973). Self-help, among other social experiments of the time, was in accord with the traditional American concepts of individual initiative and cooperative community effort. Dumont (1974) discusses this concept in great detail, saying that self-help is deeply rooted in the American traditions of pragmatism and populist movements. Having been stimulated by the social upheaval of the 1960's, self-help has come to be viewed by many as the primary source of mental health care.

The sharing of concerns and commonality evidenced by the selfhelp movement is characteristically American; our preoccupation with progress as well as our heterogeneity prod us to search unendingly for group identifications as a source of cohesion. Becoming a member of a group is a rite of passage to a new community which magically and tacitly infuses identity and pride. (Dumont, 1974, p. 631).

In addition, the self-help movement has a political dimension which articulates the aspirations of a democratic idealism: the redistribution of power. 
Hurvitz (1976, pp. 283-294), on the other hand, proposed that the origins of what he terms the Peer Psychotherapy Self-Help Group Movement developed from two different world views that came together in American life: the religious and the secular (sociological, educational). Hurvitz claims that the concepts of group confession of guilt-causing experiences to one's peers, mutual criticism, repentance, penance and mutual help between the group members were known and practiced by early American religious leaders and laymen. Because conventional psychotherapists failed the alcoholic, AA came into being, which relies upon spiritual sources of self-help. (Chafetz \& Demone, 1962, p. 161). "The secular origins of Peer Self-Help Psychotherapy Groups are found in the American ideals of democracy and humanitarianism, coupled with a psychologistic conception of human nature. These roots run parallel to the Judeo-Christian traditions and beliefs brought by the pioneers and immigrants." (Hurvitz, 1976, p. 288). For example, Recovery, Inc. started by $\mathrm{Dr}$. Abraham Low in 1937, was founded on the concepts of self-reliance and will training. The religious tradition emphasized guilt, estrangement from the group, penance and reunion with the group; whereas secular traditions emphasized individual will and responsibility.

In modern American, urbanization and industrialization coupled with increased mobility leave the individual in what Caplan (1974) terms a sustained state of "emergency arousal." The loss of a supportive network and the resultant fatigue increases the susceptibility of the individual to a wide range of physical and mental disorders. Group supports are one means of protection; the support group treats each member as a unique individual and provides an "island of stability and 
comfort in the turbulent sea of daily life." (Caplan, 1974, p. 6). Groups can also provide an effective vehicle for political advocacy for improving one's environmental situation.

Gartner and Reissman (1977), like Caplan, view the self-help movement as arising out of the needs of modern society to cope with rapid changes, the loss of traditional authority, the breakdown of institutions and the alienation that characterize our era. They also see the self-help movement as being greatly influenced by the values of the 1960's which were characterized by a concern for personal autonomy, the quality of life, consumer rights, deprofessionalization and decentralization.

In summary, mutual aid goes back to the beginnings of the human race, but the reasons people have banded together through the ages have changed. Early mutual-aid groups formed for food gathering, safety and defense. Later, occupational groups formed to better working conditions. Ethnic groups organized to cope with life in the "new land." Self-help groups for inexpensive psychotherapy evolved during the Great Depression. Groups such as AA rose out of religious and spiritual views, whereas groups such as Recovery, Inc. evolved out of the secular view. The alienation and stress of modern life have generated the need for peer psychotherapy self-help groups.

SELF-HELP GROUPS AND THE CHRONICALIY MENTALLY ILL

As previously mentioned in the introduction, one of the aims of this study is to assess the potential of self-help groups in meeting the needs of the chronically mentally ill. The chronically mentally ill represent a large number of persons who have been inadequately served by 
professional service delivery systems in the community. Consequently, the chronically mentally ill are of special concern to this project because of their lack of support networks and their high level of need. Definition of the Chronically Mentally Ill

There is considerable disagreement and confusion as to how to define the population of individuals commonly referred to as chronically menta1ly ill. Oregon House Bill 3132 defines a chronically mentally ill person as "an individual with a mental or emotional disturbance who: a) has been hospitalized twice or more in a 24 -month period; and b) needs residential and support services of an indefinite duration to maintain a stable adjustment in society." (Oregon Legislature, 1979). In contrast, the Oregon Community Support Project defines the target population as consisting of any individual who meets at least one of the following criteria:

- Has had a single episode of hospitalization of at least one year duration for the treatment of a mental or emotional disorder between 1973 and the present.

- Has had a total of 24 months of hospitalization for treatment of a mental or emotional disorder between 1973 and the present.

- In the opinion of an experienced clinician is severely mentally disabled. (Oregon CSP, 1979)

At the national level, the Community Support Program of the National Institute of Mental Health has proposed a definition of the population somewhat different than the preceding two. Obviously, a broad consensus of what delineates the target population is difficult. However, by focusing on a general description rather than a specific working definition, the chronically mentally ill may be adequately defined for the purposes of this review. Goldman, et.al. (1981, p.22) state that "the 
chronically mentally ill population encompasses persons who suffer severe and persistent mental or emotional disorders that interfere with their functional capacities in relation to such primary aspects of daily life as self-care, interpersonal relationships, and work or schooling, and that often necessitate prolonged hospital care." Fundamenta1ly, an individual who has a severe and prolonged mental or emotional disorder that interferes with his or her ability to function independently in society is a person who is chronically mentally $i 11$.

The chronically mentally ill have been described as individuals who, due to the nature of their disorders, lack adequate support systems (Lamb, 1976; Mendel, 1976; Test and Stein,1977). "Support system implies an enduring pattern of continuous or intermittent ties that play a significant part in maintaining the psychological and physical integrity of the individual over time." (Caplan, 1974, p. 7). Adequate interpersonal relationships are commonly severely strained for this population due to extreme dependency on the one hand and highly unusual behaviors on the other. Very often the friendship and family networks that the chronically mentally ill individual may once have had have become alienated from him or her over the course of the illness. The result is often a socially isolated individual with very little coping ability whose primary need, in order to survive in the community, is an ongoing supportive network.

Self-Help and the Mentally III

Silverman (1978) has proposed that one of the reasons for the formation of mutual help groups is as a response to the failure of the professional service delivery system to meet the needs of particular populations. With the advent of deinstitutionalization, ex-mental patients 
have been moved out of in-patient, 24-hour-a-day service facilities into communities ill prepared to serve this very needy population. Self-help groups which focus on the mentally ill, such as Recovery, Inc., Schizophrenics Anonymous, and Emotions Anonymous (to name but a few) have organized throughout the United States and in other parts of the world. The growth of self-help groups concerned with mental illness is indicative of the capability of these groups to provide an extensive support system to individuals with needs that are either not being adequately met or are more appropriately met via membership in a self-help organization. "The trend toward deinstitutionalization in the mental health field has important implications for the mutual aid modality. As they move out into the community, former mental patients need organizations such as Recovery, Inc, and other types of small mutual help units to aid them in their adjustment and transition to everyday life." (Report to the President's Commission on Mental Health, 1978, p. 172).

Wechsler (1961, p 48) identified eight aspects underlying the formation of ex-patient groups:

a) The mental patient on return to the community may find difficulty in re-establishing satisfactory interpersonal relations.

b) Re-establishment and maintenance of adequate social relationships are of vital importance to the former mental patient, as failures in the social sphere may serve as contributing factors in relapse and rehospitalization.

c) Opportunities should be provided for the ex-patient to meet with other individuals who would accept him, despite the stigma often associated with mental illness, and present him with the necessary supports.

d) Individuals who share the common experience of hospitalization for mental illness may tend to be more understanding, self-accepting and supportive of each other. 
e) One way of meeting these objectives is to form social groups composed primarily of former mental patients.

f) As a consequence, the ex-patient group may produce a milieu relatively freer from stress than other community life.

g) Within this sheltered social environment, the ex-patient may be able to establish interpersonal relationships more easily and develop and test various adaptive patterns of behavior.

h) As the ex-patient gains confidence from acceptace within the group and more experience in forming interpersonal relationships, it is hoped that he eventually will be able to relate to other persons outside of the protective setting.

Another perspective on professional versus self-help service is that proposed by Chamberlin (1978). An ex-mental hospital patient herself, she views the structure of the professional care-giver/patient relationship as one which fosters maladaptive dependency patterns on the part of the patient and reinforces hospital recidivism. Indeed, professionals themselves (Lamb, 1976; Mendel, 1976) have recognized the detrimental effects of treating patients as dependent and irresponsible individuals (i.e. the professional assumes the "parent" role and perpetuates patient dependence). However, inherent in the professional system of service delivery is a hierarchy wherein the patient or client is placed in a position of one who is $i l l$ or in need and the professional is placed in a position of power and competence in the provision of the needed service. In contrast, mutual help is based on a peer, reciprocal helping relationship. "(T)here is a mutual and a reciprocal quality in their (informal caregivers) interactions with the people they help. The giver and receiver of support are equally, though differently, benefited by the contact." (Caplan, 1974, pp. 15-16). According to Chamberlin (1978) the distinction between professional service and patient controlled 
alternatives is rooted in the concept of role, i.e. service provider and service recipient. Patient controlled alternatives are not service systems per se but more akin to "supportive communities" in which there are not hierarchical roles but peer relationships.

By far the largest mental health focused self-help group in existence today is Recovery, Inc., founded in 1937 by a psychiatrist, Abrahame Lowe. There are over 725 Recovery groups in the United States with over 12,000 people in weekly attendance. The organization describes itself as being an association for "nervous and former mental patients" and employs a highly structured group format using a textbook, Mental Health Through Will Training, to develop "will power" to cope with the stresses of daily living. Although some professionals think that the pitfalls of member involvement with Recovery, Inc. outweigh the advantages (Omark, 1979), other professionals think the organization serves a very useful function in the delivery of mental health services (Sheldon, 1978). Two other mental health focused self-help groups are Schizophrenics Anonymous and Emotions Anonymous, both employing a similar, highly structured format akin to that used by Alcoholics Anonymous.

Self-Help Groups for Parents and Friends of the Chronically Mentally Ill

The parents and families of the chronically mentally ill have been alternately ignored by some professionals treating their sons and daughters and held responsible for the mental illness of their offspring by other professionals. "(M) any professionals lay all the blame for the patients' problems at the parents' doorstep. Many schools of psychiatric thought implicate the patients' families in aggravating and even generating their illness." (Lamb and 0liphant, 1979, p. 86). This process of either 
ignoring patients' families or blaming them for the patients' illness has obviously served to alienate the families of the chronically mentally ill from the professional mental health system. However, it is estimated that between one-half and two-thirds of patients released from mental hospitals return to their families after discharge (Hatfield, 1979; Lamb and 01iphant, 1979). Furthermore, the 1978 Report to the President's Commission on Mental Health recommends that mentally ill patients should, when possible, live in the community near their natural support networks of families and friends. Certainly, in light of these facts, professionals can no longer afford to alienate or ignore the families of the chronically mentally ill.

Peer groups of families and friends of the chronically mentally ill have important roles to play in providing support for one another in coping with their life situation and also in pooling their experiences and knowledge base about effectively helping both themselves and their 111 relatives to live as full and meaningful lives as possible. Many family members who serve as primary care givers for mentally ill relatives have acquired coping skills for themselves and their ill relatives over years of experience with trial and error. Peer groups are able to "pool" such skills and knowledge and save much anguish for families more recently coping with mental illness. Membership in a peer group of families with a mentally ill member provides a supportive community which is frequently unavailable elsewhere. Mental health professionals have long recognized the stigmatizing of the mentally ill that has occurred by society. What professionals have failed to realize, however, is that families with a mentally ill member have also been 
stigmatized by society (and very of ten by the professional mental health system).

Parents of Adult Schizophrenics was founded when a group of parents who had schizophrenic children over eighteen years old got together and began comparing notes. They felt that they were receiving more than their fair share of the blame for what had happened to their children and that no one in the professional ranks seemed to understand this or, for that matter, the problems inherent in being the parent of a schizophrenic. (Lamb and 01iphant, 1979, p. 87).

A very important role which many peer groups of families of the mentally ill are assuming is that of advocate for adequate and appropriate care for their sons and daughters, both with government officials and mental health professionals. In Oregon, TMED, an advocacy self-help group of friends and families of the chronically mentally ill has chapters in ten different counties with a membership of over 300 and is still growing.

By its very nature, the self group can of ten accomplish more than the concerned professional alone. It has the political legitimacy of being a group of citizens organized around an issue that is important to them. Further, it has large numbers of potential members to draw on for support. Finally, such a lay group can be unruly, irreverent and committed in a way that is of ten appropriate for political activism but inappropriate for professionalism. (Spiege1, 1977, p. 771).

Professional Collaboration With Self-Help Groups For the Mentally Ill

In a survey of persons with a chronically ill relative, Hatfield (1979, p. 340) found that the highest priority of need for such persons was information about the illness and practical techniques for coping with and managing the illness. Professionals could provide a very useful and important service to peer family groups through the provision of knowledge and skills via consultation and/or workshops or seminars for the groups. The potential benefit to the mentally ill themselves, 
considering the fact that the majority of the mentally ill either reside with family members or are living in close proximity, is large in terms of improving community patient care and preventing rehospitalization. In addition, professionals with expertise in group process can provide a useful service for groups on an intermittent basis as the organization encounters difficulties in this area. The professional system also has access to resources, including finances, office space and machines that groups may need.

The Canadian Mental Health Association of Ottowa helped to form a mutual aid group of families and friends of mentally 111 or emotionally disturbed patients. This group also seeks to monitor and to influence the quality of treatment services, and works toward the improvement of after-care facilities for former patients through advocacy for new or better services. (Report to the President's Commission on Mental Health, 1978, p. 173).

Groups of families and friends of the mentally 111 have a strong potential to provide needed services for this population, to improve existing services and to advocate for services not presently available. A relationship based on a mutual partnership between professionals and self-help groups could benefit all parties concerned, especially the mentally ill themselves. Towards this end, SIS has worked collaboratively with families of the chronically mentally ill to establish an ongoing support group. In addition, SIS is consulting with a local agency in developing a self-help group for the chronically mentally ill. 


\section{CHAPTER IV}

\section{PROGRAM DESCRIPTION}

The Self-Help Information and Referral Service is an interrelated set of activities whose mission is to expand the quality and scope of human services available in the Portland area by maximizing the potential of self-help groups meeting community members' needs. As mentioned in the introduction, the goals include: (1) the development and maintenance of an accurate inventory of Portland area self-help groups, (2) the facilitation of linkage of community members interested in self-help groups with groups capable of meeting their interests and/or concerns, and (3) the acquisition of accurate information about the number of individuals in the community interested in utilizing self-help groups and the scope of their self-help concerns.

The service is realized through the interrelation of these activities. The Self-Help Project and the self-help groups collaborate to produce information about each group. The Self-Help Project provides this group information and supplemental phone staff to the central area's information and referral service ( $T r i-C o u n t y ~ I \& R$ ). Simultaneously, the Self-Help Project communicates to the community information about the service and the availability of group information through an information campaign using a specially designed poster and public service media. Some of the informed community members who become aware of the service call Tri-County I \& $R$. They are referred to existing groups if possible and this fact is recorded. If referral is not immediately possible, 
they are requested to remain on a waiting list for possible launching of new groups. The waiting list provides a pool of interested persons and an estimate of unmet demand for groups. Other estimates of community need are added to suggest which groups are needed. Further phases of the Self-Help Project include launching needed groups.

\section{MISSION AND GOALS OF SIS}

The mission of the Self-Help Information and Referral Service is to expand the quality and scope of human services available in the Portland area by maximizing the potential of self-help groups in meeting community members' needs. As mentioned in the introduction, the goals of SIS include: (1) the development and maintenance of an accurate inventory of Portland area self-help groups, (2) the facilitation of the linkage of community members interested in self-help groups with groups capable of meeting their interests and/or concerns, and (3) the acquisition of accurate information about the number of individuals in the community interested in utilizing self-help groups and the scope of their self-help concerns.

\section{NEEDS ASSESSMENT}

Assessments of needs is important for the development of a comprehensive conceptual framework for the delivery of human services. Although techniques of needs assessment have been developed for the formal system rather than the informal self-help system, certain of the usual techniques may be applicable. 
An understanding of the scope of concerns which self-help groups may address is useful as one criterion for determining the types of selfhelp groups that will be developed in the course of the project.

Estimating the range of needs for self-help groups in the Portland area entailed the following steps: (1) reviewing (a) national and local estimates of the prevalence of mental illness, (b) recently completed assessments of the community perceptions of human services needs (Tri-County Community Council, 1980), (c) data about unmet mental health needs compiled by the county Department of Human Services (1979), (d) requests for information about self-help groups from Tri-County Information and Referral Service prior to SIS (e) 1979 projections from census data and selected indicators from the Mental Health Demographics Profile System; (2) seeking information from 15 other self-help information projects throughout the nation about their services and any needs assessment techniques they have applied; and (3) ascertaining from the number of groups, number of callers for groups and the number of callers for which no groups exist the extent of met and unmet demand. Analysis of these indicators and their relation to the resource inventory is still in progress.

\section{RESOURCE INVENTORY}

The first step in developing an accurate inventory of self-help groups in the tri-county area was the creation of a data collection instrument. (See Appendix B). The inventory was drafted after review of :

The Tri-County Community Council Information and Referral's Resource Questionnaire (See Appendix C)

Self-Help Project Grant Proposal (1979) 
The AIRS National Standards (1978)

National Institute of Mental Health Planning Manual (1977)

And other materials from the Tri-County Community Council's Reference Library.

The first rough draft was revised by the project staff after examining the available information about resource inventories. Nominal Group Technique (Delbecq et. al., 1975) was utilized to obtain maximum input from all members to ensure the inclusion of the most important and relevant questions.

The inventory collects information under the following content areas: general information, membership process, meeting, services provided, professional involvement and organizational structure.

A protocol (Appendix D) was developed for using the Resource Inventory as written procedures were needed to ensure that inventory efforts were as uniform as possible. The protocol provides explicit instructions for filling out the Resource Inventory, including a definition of a self-help group and listing instructions for handling potential problems which might arise in the course of the interview. The Self-Help Project maintains its inventory by both actively searching out self-help groups (i.e. pursuing information leads about potential groups) and responding to overtures from groups that have learned of the project and would like to participate in the service. When initial contact with a self-help group is made, the resource inventory form is used to collect the appropriate information for SIS. After completion, the group inventory form is coded according to concern(s) and function(s) (See Appendix E for details of the coding system) and filed according to concern at both Tri-County Information and Referral 
service and the Self-Help Project offices. Both offices are kept informed of any changes in the status of the self-help group inventory (i.e. changes in a group's telephone number, address, etc.). In addition, the inventory is periodically reviewed and updated by recontacting each group and having the group complete a current inventory form. Thus, as accurate an information and referral service as possible is provided.

\section{POTENTIAL MEMBER INVENTORY}

In addition to the group inventory form, the project has also developed a potential member inventory form (Appendix F) collaboratively with the staff of Tri-County Information and Referral. The potential member inventory form is divided into two parts: the first part capturing the basic information necessary for an individual to be referred to an appropriate self-help group (i.e. the problem or concern that the individual has and any possible limitations to group attendance), the second collecting demographic information (on a voluntary basis) for later research purposes. An effort was made to keep the potential member inventory as brief as possible so as not to infringe on the privacy of potential members or disrupt the usual referral procedures of the Tri-County Information and Referral Service.

The potential member's need or concern is coded from the master coding list according to the specific concern expressed by the individual and matched with a self-help group with the same or a compatible concern if such a group is available. If no appropriate group for meeting the caller's concern is presently available, the potential member is asked if $s /$ he is willing to be put on a waiting list to possibly help form or participate in such a self-help group at a later date. The "waiting list" 
is periodically reviewed and referrals made from it as new groups are created or as existing groups become open to new members.

\section{INFORMATION CAMPAIGN}

A major goal of the Self-Help Information Service is to Iink community members with concerns to specific groups available to meet those concerns. In order to facilitate this linkage function, an information campaign was developed to inform the community about the existence of the service. The information campaign utilized four media: a poster for distribution over the tri-county area, a press release and cover letter, a public service announcement and cover letter for radio, and a public service announcement for television.

The poster was produced through the joint efforts of Project staff and other professionals who donated their time and skills to design and produce the poster. The Project staff compiled an exhaustive list of agencies, organizations and businesses that would eventually receive posters. This list included high schools, community colleges, universities, health and mental health agencies, businesses, government and other public and community organizations and agencies, and religious organizations in the tri-county area--Multnomah, Washington, and Clackamas counties. This list was further subdivided into geographical areas which could be managed by individuals delivering posters.

As soon as the printed posters arrived, staff members and volunteers distributed as many posters as possible before Christmas and during the highly stressful Christmas season. By February 1, approximately 800 posters had been distributed by eight to ten staff members and student volunteers. 
A press release was sent to commercial, university and community newspapers. An attempt was made to integrate into the press release the ideas, concepts, style and phrasing used in the poster. One newspaper, the Oregon Journal, followed up on the press release with a feature story on the Self-Help Information Service.

In mid-December a public service announcement was released to 18 radio stations in the tri-county area. The announcement was a condensation of the poster copy, retaining its style and some of the same phrasing in an attempt to tie together the varying elements of the information campaign and thus provide continuity.

As of this date, preparations for a public service announcement for television are in process. A television station is willing to assist in the production of the public service announcement and is shooting a slide of the modified poster artwork which they will then air periodically as a public service announcement for the Self-Help Information System. In addition, the station will make duplicate slides and distribute them to the rest of the local television stations in Portland.

Project members are also available to speak on radio and TV talk shows about the Self-Help Information Service and self-help groups in general and to give interviews about the service to reporters for newspaper publication.

COLLABORATION WITH TRI-COUNTY INFORMATION AND REFERRAL

SIS is fortunate to have the cooperation of the existing Tri-County Community Council Information and Referral Service in the provision of the 40-hour per week Self-Help Information Service. The telephone service is integral to achieving the SIS goal of linking needy community members to 
groups capable of meeting those needs. The SIS telephone service was originally projected to be staffed entirely by project personnel and operate for 30 hours per week. However, collaboration with Tri-County Community Council Information and Referral Service has expanded SIS into a 40-hour per week telephone referral service, primarily staffed by Tri-County with additional part-time personnel provided (16-24 hours per week) by the Self-Help Project. The staff of Tri-County Information and Referral has agreed to integrate SIS into their onging service delivery system, potentially enabling a long-term perpetuation of SIS. Both organizations collaborate for their mutual benefit--the scope of the TriCounty Community Council Information and Referral Service is broadened to include self-help groups and the Self-Help Project has a 40-hour per week telephone service. 
CHAPTER V

\section{RESEARCH DESIGN AND METHODOLOGY}

This study of consumer satisfaction was a formative evaluation which means that it was designed for the results to be used to modify SIS as a result of the criticisms and suggestions of the consumers and staffs involved in this study. An ex-post facto design was utilized. Questionnaires were developed for the four samples involved in this study to measure their satisfaction with the service.

\section{PARTICIPANTS IN THE STUDY}

Specifically, the participants in this evaluation included:

(1) the six person staff of Tri-County Community Council Information and Referral ( $I \& R$ staff); (2) the six person Project staff and four students (Project staff); (3) the 44 persons who called the Self-Help Information Service (callers) and were not immediately referred to a group including those who are presently participating in a group, those who dropped out of a group, those who were not referred to a group, those who were referred but did not make contact with the group, and those who were referred and made contact but did not attend or join the group; (4) and 25 groups 1isted with the Self-Help Information Service (groups). The first three sets of participants were 100 percent samples; the self-help group representatives were an 18 percent random sample of the 136 self-help groups inventoried. Two callers were not interviewed because they could not remember their contact with the service. Of the 
surveyed groups, one was defunct and, therefore, was not interviewed. The sample of groups was chosen using a Table of Random Numbers; twentyfive groups were included in the sample because the Project's statistical consultant suggested that this was a stastically adequate and practical number.

\section{METHOD OF STUDY}

This evaluation of SIS was carried out during February and March of 1981. Separate interview schedules were developed by the evaluation team with one schedule being targeted at each of the four samples involved. The Project staff and $I \& R$ staff questionnaires were pretested by presenting the instruments to each staff person for comments and recommendations for revision. Soliciting feedback from the prospective respondents assured higher validity in that the evaluators were assured they were measuring variables the staff believed important and that the questions actually collected relevant data to measure those variables. The caller questionnaire was pretested on a caller who agreed to participate in this matter. The group questionnaire was not pretested.

Single measurements were taken of the four samples after contact with the service (ex-post facto design). One measurement of conditions which existed prior to the establishment of the service was available-the number of requests for referrals to self-help groups is tabulated at Tri-County Information and Referral on a monthly basis and this data was compared with post-SIS requests for self-help groups. This will be discussed in the next section under $I \& R$ Staff Results. By asking for retrospective self-reports from participants on their statuses prior to contact with SIS, the interview schedules provided a pseudo-pretest 
measure. Other measurements collected information on status and levels of satisfaction after contact with the service.

The interview schedules ask for data from each sample as outlined below:

For $I \& R$ staff

- Understanding of the protocol and technical procedures around the service.

- Satisfaction with the ways self-help groups are inventoried.

- Comfort with the potential Member procedures

- Comfort with the Group Inventory procedures

- Overall satisfaction-how has SIS improved your service or how has SIS impacted upon I \& $R$ negatively?

- What would make SIS better and more effective?

- How have attitudes of SIS members been towards I\& $R$ staff?

\section{For Project staff}

- Understanding of the protocol and technical procedures around the service.

- Satisfaction with the way self-help groups are inventoried.

- Comfort with the Potential Member procedures and time spent on related tasks.

- Comfort with Group Inventory procedures and time spent on related tasks.

- Comfort with the Information Campaign procedures and time spent on related tasks.

- Satisfaction with the speed of the referral process.

- Overall satisfaction with SIS.

- What would make SIS better and more effective?

- How effective is SIS? 
- Attitudes of Project staff towards each other.

- Specific questions aimed at the principle investigator, the project director, the research assistants and the students.

\section{For Callers}

- Promptness of service.

- Ease of obtaining service.

- How treated by personnel.

- Effectiveness of service.

- Reasons for non-utilization of the referral information.

- Strongest aspect of the service.

- Weakest aspect of the service.

- Recommendations for improvement of the service.

\section{For Groups}

- What impact has the service had on your already existing group?

- What could be done to improve the service?

\section{DATA COLLECTION}

The interviews began during the last week of February, 1981. The I \& $R$ staff and the Project staff were interviewed in person by the evaluators; the callers and the groups were interviewed over the phone by the evaluators. The interviews were completed within three weeks.

I \& R staff and Project staff had been informed of the evaluation and interviews several months before the interviews occurred. Each interview took 10 to 15 minutes to complete. Callers were contacted by telephone and were asked if they would participate in a short interview for purposes of an evaluation of the Self-Help Information Service. They 
were also asked if the interviewer was interrupting at a difficult or busy time, and if the response was affirmative, arrangements were made to re-contact the interviewee at a better time. This interview took 10 to 20 minutes to complete. The contact persons for the groups in the sample were contacted and asked to participate in the same manner as the callers were asked; the interviews for these participants took less than five minutes.

\section{DATA ANALYSIS}

The questionnaires consisted primarily of fixed-response items with a few open-ended questions to add richness to the study. The fixedresponse data were tallied and organized into tables of frequency and proportion. Open-ended data were organized into general categories and then tallied. (Appendices G, H, I, and J). The findings were interpreted by comparing present conditions to the conditions of the respondents when the service began in December, 1980, by how well the service has met Project staff expectations and by comparing SIS to other Self-Help Information and Referral Services around the country. (Appendix A). 
CHAPTER VI

RESULTS

The results are presented in four sections corresponding to the participant groups involved in the study: (a) Self-Help Project staff, (b) I \& R staff, (c) groups, and (d) callers. (See Appendices G, H, I and J.)

\section{SELF-HELP PROJECT STAFF QUESTIONNAIRE}

All ten staff persons from the Self-Help Project were interviewed in face-to-face interviews and asked thirty questions, twenty-four of which were closed-ended and four of which were open-ended. (See Appendix K). In addition, the staff was divided into four different categories (principal investigator, project director, research assistants and students) and each staff person was asked one or more specific questions in relation to his or her particular role in the project.

The Self-Help Project Staff Questionnaire included brief summaries of the goals and objectives of SIS which were designed to remind the staff of the specific aims which SIS has attempted to fulfill. Staff members were probed concerning three functional aspects of SIS:

(1) satisfaction with their particular roles in SIS, (2) satisfaction with SIS in regards to its effectiveness in achieving the goals and objectives of SIS and (3) satisfaction with their own competence in fulfilling their particular function in the operation of SIS. The questions covered three content areas: (1) the self-help group 
inventory, (2) the potential member inventory, and (3) the information campaign and also two summary areas: (1) collaboration with Tri-County Information and Referral and (2) overall satisfaction with SIS. Furthermore, staff suggestions, comments and criticisms regarding all aspects of SIS were solicited in open-ended as well as closed ended questions.

Findings

Self-Help Group Inventory. In brief, the majority of the staff were satisfied with all aspects of the self-help group inventory process: time required, usefulness of the form and the procedures and directions given. More specifically, the entire staff of the Self-Help Project was satisfied with the amount of time each spent on the inventory of selfhelp groups. Eight staff persons thought the inventory was either very useful or useful for collecting the information necessary for the operation of SIS and the research goals of the Project. Two did not. While most staff thought that the procedures for using the group inventory form were adequate and comprehensive, two staff members thought they were cumbersome. The directions for using the self-help group inventory questionnaire were thought to have been clear by seven staff, not clear by one and not applicable to two staff persons. In addition, half of the staff stated they were comfortable or somewhat comfortable contacting groups to inventory them.

Potential Member Inventory. The majority of the staff were satisfied with all aspects of the potential member inventory process: time required, usefulness of the form, and the procedures and directions given. In specific, almost all Self-Help Project staff persons were satisfied with the amount of time each spends on the inventorying of 
of potential members to self-help groups. In addition, eight staff thought that the potential member inventory form was either very useful or useful in capturing the information needed by SIS and the research project, though two staff persons did not know how useful the form was. There was a single staff person who was uncomfortable contacting potential group members and who thought that the directions for utilizing the potential member questionnaire were unclear. Two staff thought that the procedures for using the potential member form were sketchy and inadequate. A majority of the staff, however, thought the procedures and directions were comprehensive and adequate and clear. Furthermore, a majority of the staff were also comfortable contacting potential group members.

Information Campaign. In brief, the majority of the staff were also satisfied with all aspects of the information campaign: time required, usefulness of the poster, and the procedures and directions given. Nine staff were satisfied with the amount of time each spent working on the information campaign, but one staff person was not and thought that the information campaign (specifically the delivery of SIS posters) took too much Project staff time and energy and consequently was ineficient. The entire staff was unanimous in thinking the SIS poster was either very useful or useful in conveying the necessary facts about SIS to the public. Six to eight staff were comfortable disseminating information about SIS, thought there had been clear directions given for the process and thought the procedures for the information campaign were adequate and comprehensive. However, two staff thought the procedures for the information campaign were sketchy and 
inadequate, the directions were not clear and were uncomfortable disseminating information about SIS.

Collaboration With Tri-County Information and Referral Service. The large majority of Self-Help Project staff were satisfied with the amount of time each spent working at Tri-County Information and Referral Service, thought $s /$ he received satisfactory training to work at the service and were satisfied with the attitudes of other staff persons towards him/her. Nine staff were either satisfied or very satisfied with the amount of time each spends working at or with Tri-County Information and Referral Service. One was less than satisfied with the time s/he spent at Tri-County Information and Referral Service and thought $s /$ he received unsatisfactory training for working at the service. However, most staff thought their training was either very satisfactory or satisfactory. Almost all the staff thought the attitudes of Tri-County's staff towards them as a co-worker was either very satisfactory or satisfactory.

Overall Satisfaction With SIS and the Self-Help Project. In brief, the entire staff was satisfied with the overall performance of SIS. More specifically, in evaluating their satisfaction with all aspects of SIS combined, the entire staff of the project were either satisfied or very satisfied. The principal investigator responded that SIS was more than fulfilling his expectations as conceived of in his grant proposal for the project. The project director was very satisfied with the proportion of staff time and energy invested in SIS and thought SIS was very useful in furthering the attainment of the overall research goals of the project. Three student staff thought that their participation 
in SIS was very or somewhat useful in expanding their knowledge base of self-help groups and research. One student staff did not find his/her participation in SIS useful in expanding his/her knowledge base and suggested that students be given structured orientation sessions to the project and more of an opportunity to consult with the staff. All four research assistants thought their involvement with SIS was very usefuI experience for their professional growth.

Project staff were satisfied with the way SIS handles referrals to self-help groups. Three staff thought that consistent and explicit procedures for using the potential member inventory could improve the quality of the referral service delivered by SIS. One suggested more publicity of the service and better coordination with Tri-County Information and Referral as a means of improving SIS.

The most frequently mentioned responses for improving the functioning of SIS were the development of explicit, written procedures for processing potential member contacts and a larger publicity and public relations campaign to increase the volume of both self-help groups and potential members using the service. In addition, two staff thought better collaboration and cooperation with Tri-County Information and Referral Service was needed for a consistently high quality of service delivery and to ensure the achievement of the project's research goals. The project director recommended the assignment of at least one staff person to oversee the entire operation of SIS and the assignment of responsiblity for the management of particular operations of SIS with specific staff persons. Furthermore, she recommended that SIS operations and procedures be systematized and written into protocol with built-in quality assurance checks. 
$\underline{\text { Summary }}$

Nearly all staff were satisfied with all aspects of the self-help group inventory process: the time required, the usefulness of the inventory form, and the procedures and directions for inventorying the groups; the potential member process; and the information campaign. Self-Help Project staff were satisfied with the amount of time spent working at Tri-County Information and Referral Service, believing they had received satisfactory training to work at the service. SelfHelp Project staff perceived the attitudes of the Tri-County I \& $R$ staff towards them as positive. Furthermore, the majority of the staff was satisfied with the overall performance of SIS in meeting its objectives, the broader project objectives, and the staff's own personal objectives. Simply stated, Self-Help Project staff satisfaction with SIS was high.

I \& R STAFF OUESTIONNAIRE

Utilization Data

The Self-Help Information Service is a collaborative effort involving Tri-County Information and Referral and the Self-Help Project.

Data provided by $I \& R$ shows that SIS has had an impact on the number of calls coming into $I$ \& $R$ during the nine month period of July 1980 through March 1981. The service started up in January 1981 and the data shows a noticeable 300 percent increase in calls asking for self-help information starting at that time. The subsequent decline may indicate the need for repeated bursts of "advertising" for the service. (See Figure I). 


\section{FIGURE 1}

IMPACT OF SIS ON NUMBER OF CALLS TO I \& $R$

ASKING FOR SELF-HELP INFORMATION

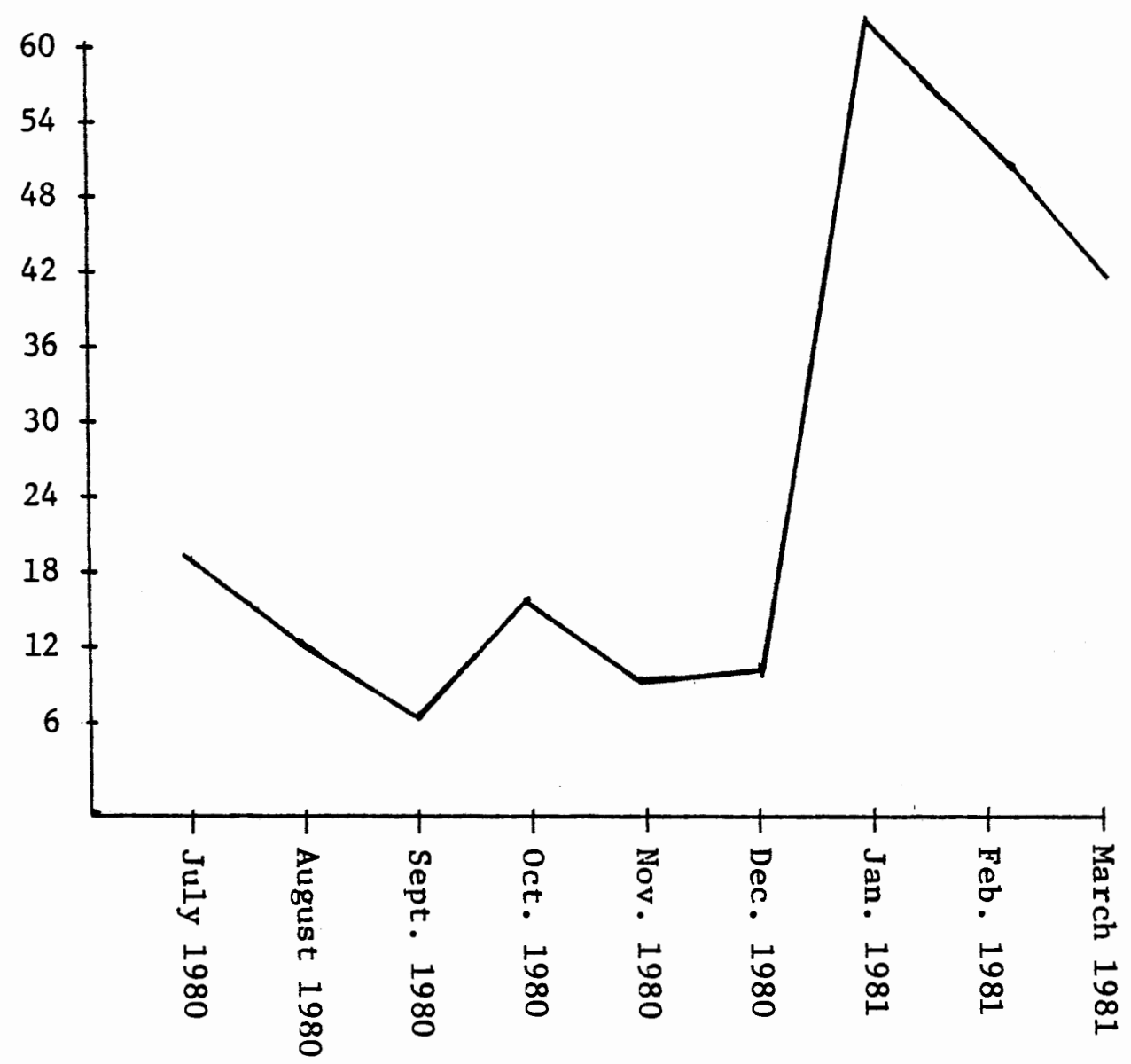

Sample

The six staff (100 percent sample) of Tri-County I \& $R$ were asked about the main procedures for using the Potential Member forms, procedures for using the Group Inventory Form, satisfaction with the referral procedures, satisfaction with the exchange of services between $I \& R$ and SIS and general satisfaction with SIS. (See Appendix L for questionnaire and Appendix $\mathrm{H}$ for questionnaire results). 
Findings

The results of this survey of $I$ \& $R$ staff indicate that satisfaction with SIS is high even though imperfect procedural understanding and coordination is evidenced at this time.

The first part of the questionnaire was designed to assess the knowlege of $I$ \& $R$ staff regarding the appropriate uses of the Potential Member forms and the Group Inventory forms. The use of these forms constitutes the major tasks SIS staff asks I \& $R$ to perform. These forms provide the informational base for the Self-Help Information Service and also are important for furthering the attainment of the research goals of the Self-Help Project.

Regarding the use of the Potential Member forms, the I\& $R$ worker was asked to describe the procedures for use of the form in two different instances--when a self-help group is available for referral and when a self-help group is not available for referral. When a group is available, the worker should proceed through five steps. No one on the staff stated all five steps; most of the steps were mentioned by only one and sometimes two workers. When a group is not available, the worker should proceed through three steps. These procedures were better known by $I \& R$ staff with five workers mentioning two of the steps involved. There are four steps involved in the procedures around the Group Inventory forms; about half of the staff were knowledgable of these steps.

One-half of the $I \& R$ workers felt clear or somewhat clear orientation had been given to work with the potential member forms. When questioned about the Group Inventory forms, only one worker thought clear directions and training had been given. Most of the staff thought they did not have a picture of the total system of the Self-Help Information 
Service such as where the forms go and when and how the forms are used. When the staff was asked if orientation designed to give a view of the total system would be helpful, almost all responded affirmatively.

An assessment of the impact of the potential member procedures on the functioning of the staff at $I$ \& $R$ was made. One-half of the workers are comfortable responding to telephone requests for referrals or further information about SIS. However, two workers think the procedures are cumbersome while two think they are comprehensive and adequate. Regarding the Group Inventory forms, almost all of the staff are comfortable responding to telephone calls from self-help group members asking to register their groups with SIS or for further information about the service. Two workers think these procedures are cumbersome while three think the procedures are comprehensive and adequate.

One-half of the staff responded when asked how Potential Member procedures might be improved. All of these respondents wanted to limit the data collected to name, telephone number and concern of the caller because time and tact limit their ability to obtain all the desired information at the time of initial contact, and they thought Project staff could collect the rest of the information at the time of re-contact. When asked how Group Inventory procedures might be improved, one person responded recommending that inventory procedures be incorporated into the data collection and file up-dating system of Tri-County Information and Referral.

To summarize responses on the Self-Help Information Service procedures, all of the staff felt the procedures were smooth (non-disruptive) and two workers felt the service had a facilitative impact on I \& $R$. 
Well over half of the staff thought that referrals are made promptly to potential members when a group is available and that referrals are appropriate. Almost all of the staff did not know if they were satisfied with the way SIS handles referrals when a group is not immediately available for the caller and the contact information is sent to SIS staff. Two workers suggested that feedback to I \& R would be helpful. Specifically suggested were informing the $I \& R$ worker when the call-back will be made by SIS and what action (i.e. referral) was taken with the potential member.

The collaborative, exhange arrangement of "person power" and resources between $I \& R$ and Project staff is described as being satisfactory or very satisfactory by all of the I \& $R$ staff. Likewise, all of the staff state that the attitudes of SIS staff toward the I \& $R$ worker have been satisfactory or very satisfactory.

The extent to which SIS has reached its goal of expanding the scope of $I \& R$ resources to include self-help groups in the Tri-County area was measured; most of the staff felt SIS had greatly expanded or somewhat expanded $I \& R$ resources. The $I \& R$ staff was also asked to evaluate the effectiveness of SIS in reaching the over-all goals of increasing I \& R resources, linking self-help groups and prospective members and providing accurate information about self-help groups to prospective members; all of the staff felt SIS was effective or very effective in reaching the stated goals. Suggestions for making the service even more effective focused on the need for more publicity-one person said "time, experience and exposure" would add to the effectiveness. All of the staff thought the Self-Help Information Service improved or greatly improved Tri-County Information and Referral efforts. 


\section{Summary}

I \& R staff were considerably lacking in knowledge of the procedures for using the Potential Member forms and the Group Inventory forms.

While one-half of the workers thought clear orientation had been given for using the forms, most workers stated they did not have a picture of the total system of the Self-Help Information Service. Almost all staff thought orientation designed to give a view of the system would be helpful.

Suggestions for improving the service were to limit the amount of data collected at $I \& R$ and to receive feed-back from Project staff about the action taken with referrals such as when the person was called back and what referral was made.

All of the staff felt SIS was effective in reaching the stated goals of the service and agreed that SIS efforts improved the Tri-County Information and Referral Service.

\section{SELF-HELP GROUP QUESTIONNAIRE}

Twenty-four of the 136 self-help groups inventoried were contacted and completed questionnaires. The questionnaires asked about self-help group contact with SIS, helpfulness of SIS, and satisfaction with SIS; comments and criticisms were also solicited from the groups. (Appendix M.)

\section{Findings}

In brief, the groups contacted were evenly divided regarding whether SIS had been helpful to the group or not, but a majority of the groups were satisfied with their contact with SIS. More specifically, one self-help group (.04 of the total sample) thought that having their group registered with SIS had been very helpful to the group (i.e. provided 
the group with new members, favorable notice, etc.), .38 of the total sample thought that registration with SIS had been helpful, .38 thought that registration was unhelpful and .20 of the groups did not know whether registration of their group had been helpful or not. In the process of implementing the self-help group questionnaire, ambiguity became evident regarding the response "unhelpful." For the purposes of evaluation, an "unhelpful" response was defined as being equivalent to a response of "made no difference."

When asked how satisfied they were with their contact with SIS, .38 of the self-help group contact persons responded very satisfied, .33 responded satisfied, and .29 responded that they did not know how satisfied they were with their contact with SIS. Two prominent reasons emerged during the evaluation for a contact person not knowing how satisfied $s /$ he was with SIS. One was that the individual contacted for the interview had never personally had any contact with SIS (i.e. other group members had contacted SIS) and $s /$ he was unfamiliar with the group's relationship with SIS. Another frequent reason given for unknown satisfaction with SIS was that the contact person had no way of knowing whether SIS had a favorable impact on their group (i.e. provided new member referrals to the group) or not.

Self-Help Group Suggestions/Criticisms Regarding SIS. The most frequent comment or suggestion given by self-help group contact persons for improving the operation of SIS was that more publicity of SIS was needed. This would generate more referrals to the self-help groups inventoried by SIS which was the next most frequently mentioned suggestion for improving SIS. In addition, more information about the operation and functions of SIS was desired by the groups so that they 
would better know how to maximize their group's benefit from SIS. Some respondents thought that an increased role of SIS, inclusive of followup on self-help group referrals and the provision of auxilary services (including clerical resouces and technical advice on launching and maintaining self-help groups) would enhance their group's benefit from SIS and hence improve the functioning of SIS.

\section{$\underline{\text { Summary }}$}

The self-help groups surveyed were almost evenly divided regarding whether or not SIS had been helpful to their group. However, none of the groups surveyed thought that SIS was a hindrance to their group. In addition, .71 of the groups were satisfied with their contact with SIS and the remaining groups did not know how satisfied they were with SIS (no group was dissatisfied with SIS). These results indicate that SIS has had a favorable influence on a large proportion of the groups inventoried. (See Appendix I for the actual results.)

\section{CALLER OUUESTIONNAIRE}

Sample

As Figure 1 shows, 112 people called SIS to obtain varied information about self-help groups during January and February 1981, the time during which this evaluation was done. Of these 112 callers, 44 were referred to the Self-Help Project because the referral could not be made immediately by the $I$ \& $R$ worker. Therefore, the 68 callers who were immediately referred to a group by $I$ \& $R$ or given information are not included in the sample of callers involved in this evaluation of the service. The $I$ \& $R$ staff have been asked by Self-Help Project staff to 
inform the latter of all referrals made through the Self-Help Information Service so that when an evaluation is done in the future the sample will include all consumers of the service and not just those participants for whom a group was not imnediately available and a referral could not be made. Obviously, if callers who could not immediately be helped are the only consumers surveyed, the results may reflect a negative bias. The 44 consumers (callers) of the Self-Help Information Service were contacted (see Appendix $N$ ) and asked to participate in an evaluation of the service. Of the 44 in the population, one person could not remember being contacted by the service due to memory loss and one person was mistakenly included--she had never actually had contact with SIS. Therefore, $N=42$ in this discussion of the results of the Caller Questionnaire. (See Appendix $J$ for the actual questionnaire results.)

Findings

Although only 7 percent of the callers are still participating in self-help groups as a result of their contact with SIS, almost all of the respondents were satisfied with the service they received from SIS.

Most of the respondents contacted Tri-County I \& $R$ (222-5555) about a self-help group. Of these, almost all indicated the worker at $I \& R$ was friendly and helpful. Very few of the callers were referred by Self-Help Project staff to $I \& R$ or by $I \& R$ to Project staff, but of these, most said both places gave consistent information. Most of the callers indicated they had no difficulty finding out about or contacting SIS. Of the few who did have difficulties, three people indicated they were unaware of SIS because there was not enough publicity. One person said I \& $R$ lacked the specific information she needed about self- 
help groups; one person said it took a couple of months to get a group launched; one person said the SIS person she was to talk to was out of the office and one person said call-backs by SIS took too long.

Almost all of the callers felt neutral to very positive about calling the service and called about membership for themselves in selfhelp groups. Of the respondents not calling for membership in a group, three were professionals calling for clients, three wanted further information, two were calling for a friend and one was interested in a directory of self-help groups. Most of the callers indicated they were very satisfied or satisfied with the responses to their requests which they received from the service.

Over half of the callers were referred to a group, either immediately or later. (See Figure 2 for a graph depicting the way in which the respondents funnel down through the referral process described in this paragraph.) of these, most had no trouble contacting a group representative. Of the callers referred to a group, less than half had attended group meetings and most of these people had attended only one meeting. of the people who had not attended meetings, four respondents said the group had not started yet, five said they were too busy and had not had time to contact the group and six respondents stated various reasons such as lack of transportation or that it was too far to travel to the self-help group which they had been referred to. Of the callers who attended a group meeting at least once, almost all stated that the referral was an appropriate one. Of the nine respondents who had attended at least one group meeting, two indicated they felt much better, two said they felt better, and four indicated they felt just the same. About half stated the concerns and interests of the group members were 
similar to theirs and were still attending group meetings. Of the five respondents who said they are not still attending meetings, one person said the group was not what $s /$ he wanted in a group; one person was too busy to attend and had a time conflict; one person was a professional observing the meeting; one person said the age range of the group was "wrong" and one said the group was too depressing. Of the four callers who were still attending meetings, three stated their needs and concerns are being met by the group and that they plan to continue attending meetings in the future.

FIGURE 2

HOW RESPONDENTS FUNNEL DOWN THROUGH THE REFERRAL PP.OCESS

\begin{tabular}{|c|c|c|c|c|c|}
\hline $\mathrm{N}=42$ & $\mathrm{~N}=24$ & $\mathrm{~N}=9$ & $\mathrm{~N}=8$ & $N=4$ & $\mathrm{~N}=3$ \\
\hline $\begin{array}{l}\text { Total } \\
\text { number of } \\
\text { callers not } \\
\text { immedlately } \\
\text { referrable } \\
\text { to a group; } \\
\text { respondents } \\
\text { of the } \\
\text { study }\end{array}$ & $\begin{array}{l}\text { Respondents } \\
\text { referred to } \\
\text { a group }\end{array}$ & $\begin{array}{l}\text { Respondents } \\
\text { who have } \\
\text { attended } \\
\text { at least } \\
\text { one group } \\
\text { meeting }\end{array}$ & $\begin{array}{l}\text { Respondents } \\
\text { who thought } \\
\text { the referral } \\
\text { was } \\
\text { appropriate }\end{array}$ & $\begin{array}{l}\text { Respondents } \\
\text { who stated } \\
\text { the concerns } \\
\text { and } \\
\text { interests } \\
\text { of the group } \\
\text { meeting were } \\
\text { similar to } \\
\text { theirs and } \\
\text { were still } \\
\text { attending } \\
\text { group } \\
\text { meetings }\end{array}$ & $\begin{array}{l}\text { Respondents } \\
\text { who plan } \\
\text { to continue } \\
\text { attending } \\
\text { group } \\
\text { meetings }\end{array}$ \\
\hline Henowny & & 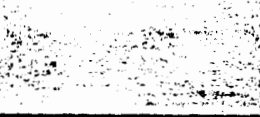 & 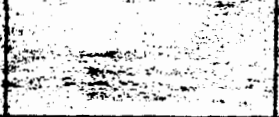 & $-2,-4$ & 20 \\
\hline
\end{tabular}


of the total population of callers, slightly over one-half were asked to be on a waiting list to form a group; almost all of these agreed to be on a list and indicated they were satisfied with this arrangement.

Most of the respondents were told that the SIS staff would recontact them and of these, the SIS staff did recontact four-fifths of them. Almost all the callers who were re-contacted stated that the SIS person was friendly and helpful.

of the total population of respondents, slightly less than half stated they would be available and willing to help form a group if the opportunity arose. Of these, most had not yet had the opportunity to help form a group. Of the two respondents who had been involved in launching groups, both stated the procedures for forming a group develooped by SIS staff were helpful.

Most of the callers stated that SIS provided them with accurate information and said they would refer a friend or relative to the service. Overall, almost all respondents were satisfied or very satisfied with the service they received from SIS.

When asked for specific reasons for satisfaction/dissatisfaction with the service, three-fourths of the responses were positive, making comments about (a) the friendly service, (b) SIS supplying needed information in a meaningful, helpful way, (c) SIS staff being concerned about the individual and (d) the positive feeling conveyed by SIS staff that something could be done to help the caller. The reasons for dissatisfaction were: (a) that it took too long to get a group going, (b) one person was not re-contacted as promised, (c) one referral was inappropriate and (d) much of the potential for SIS was "unrealized" yet. 
$\underline{\text { Summary }}$

Slightly more than half of the callers initially unreferrable were referred to a self-help group after a second contact at a later point in time. Less than half of those referred actually attended a group meeting and one-third (three) of those people plan to continue attending meetings. In spite of this low number of people actually linked to groups, almost all respondents were satisfied with the service they received, stating SIS was friendly, helpful, concerned, optimistic and able to supply needed information. 
CHAPTER VII

SUMMARY, RECOMMENDATIONS AND DISCUSSION

Summary of Findings

The Self-Help Information Service. The majority of the Self-Help Project Staff were satisfied with the overall implementation performance of SIS in meeting the service's objectives, the research project's objectives and the staff's own personal objectives. In addition, most project staff were satisfied with the self-help group inventory process, the potential member inventory process, the information campaign and the amount of time each spent working at Tri-County Information and Referral Service.

All of the I \& $R$ staff thought SIS was effective in reaching the stated goals of the service and agreed that SIS efforts improved the $I \& R$ service resource base. Referrals to self-help groups through $I \& R$ tripled upon the advent of SIS. I \& $R$ staff were lacking in procedural knowledge of SIS and did not have an understanding of the total system of the Self-Help Information Service. The staff agreed that orientation designed to give a view of the system would be helpful to them.

The self-help groups surveyed indicate that SIS has had a favorable impact on a large proportion of the groups inventoried. One-half of the groups indicated SIS had been helpful and three-fourths indicated they were satisfied with their contact with the service. 
Almost all of the callers for whom there had been no immediate referral possible were satisfied with the service they received from SIS. They felt the service was friendly, helpful and able to supply needed information. Seven percent of these callers are currently participating in self-help groups as a result of their contact with SIS.

In summary, the results of the survey of staff and consumer satisfaction with SIS indicate both $I \& R$ and Project staff were satisfied with the overall performance of SIS and agreed SIS was effective in reaching the stated goals of the service. Of the consumers surveyed, the groups were satisfied with their contact with SIS and the callers indicated they were satisfied with the service they had received.

The SIS and Other Projects. Three other self-help information and referral services were located in the United States: (1) the Long Island Self-Help Clearinghouse, 01d Westbury, New York, (2) the New York City Self-Help Clearinghouse, New York, New York, and (3) the Westchester Self-Help Clearinghouse, White Plains, New York. (See Appendix A.) SIS and the three New York clearinghouses all utilize a group inventory form to collect the basic information necessary for referrals to be made to a group. The clearinghouses, like SIS, also provide consultation to groups, assist in launching new groups for which there is an unmet need, and conduct research on various aspects of self-help groups. The self-help clearinghouses are very similar to SIS in terms of the breadth and scope of the services offered to self-help groups and the community. In addition, they also have a similar interest in expanding the knowledge base of self-help groups by conducting research on the groups. Though SIS developed independently of the three New York clearinghouses, great similarities and no major differences are apparent 
between the organizations. The Self-Help Project plans to contact these services to compare factors such as cost, volume, administrative structure and organizational linkages.

\section{RECOMMENDATIONS}

In reviewing the results of the four questionnaires, the most frequently mentioned recommendation for improving the operation of SIS was that a larger public relations campaign was needed. The community must know the service exists and that they may access it. Greater publicity of the service would increase the volume of referrals to selfhelp groups and the number of groups inventoried.

Another frequent suggestion for improving SIS was the development of specific, systematic, written procedures with built in quality assurance checks for processing contacts with potential group members. These procedures are in preparation.

Collaboration between Tri-County I \& $R$ and the Self-Help Project should be improved by having a training program for Tri-County staff to orient them to the SIS. The program should provide Tri-County I \& $R$ staff with an overview of the system and training in the specific procedures used for the operation of SIS.

More detailed recommendations and actions are under consideration by Project staff.

\section{DISCUSSION}

This participant satisfaction study is seen as the initial piece of a jigsaw puzzle of evaluation for a self-help information service. It 
is important to communicate to other actual or potential self-help information services the detail of this particular piece of the puzzle and the outline of its future companion pieces.

The Self-Help Information Service is still in its infancy, having been in operation for only two months at the time of this evaluation. Therefore, we are measuring a time period corresponding to the initial implementation of a fledgling system.

It is appropriate during early system stages to focus on participant satisfaction, specifically the reactions of the staff persons involved in launching a system, and the reactions of groups and callers to the instigation of the service. This important information reassures administrators when participants, whatever their position, experience high satisfaction with the system and, the recommendations provide invaluable aid to fine-tuning the service.

It is appropriate in this early stage evaluation to focus on process variables and emphasize outcome variables minimally. It is necessary in subsequent evaluations to look more closely at the volume and effectiveness with which the system functions.

Specific results indicate to program developers specific small studies necessary to maximizing the program. For instance, our initial follow-up suggests that many callers do not follow through with referrals given them. A small focused telephone follow-up of persons who planned to attend groups but did not is now in progress in order to learn something of the experience and barriers to attending a group.

As the analyses proceed on the inventory of self-help groups, Project staff can better assess the breadth and depth of the self-help groups which exist and perhaps the converse, the areas of need in which 
self-help groups do not exist. The callers who request groups for concerns which are not represented in existing groups are a prime source of information for groups to be launched. Areas such as more women's groups, mixed-sex rap groups, step-parent groups, etc., provide indication of groups which may be launched later in the research-action sequence. In sum, we domonstrate initially that people who have taken part in the information service experience high satisfaction and that such a service can be done for a reasonable amount of effort over a relatively short span of time. In order for this to happen, collaboration, good will and frequent cross-communications with existing information and referral services were necessary. The evaluation of this service gives both administrative reassurance and direction to improve the project. Episodic replication of this evaluation and additional focus on system effectiveness, needs of the community, group resources within the community, and the dynamics of non-participation round out this administrative evaluation of the Self-Help Information Service.

This research project described the development, implementation, and evaluation of the Self-Help Information and Referral Service. Because of the authors' beliefs in the value and efficacy of self-help groups, it is hoped that similar projects across the country undertake to develop such services for their communities. Certainly a paucity exists in the literature of current detailed descriptions of the development of information services aimed at self-help groups. It is hoped that this research may prove useful to others who undertake such a project in the future. The evaluation provides specific recommendations which will be used to modify the service in an attempt to enable SIS to better serve the needs of self-help groups and the community. 


\section{APPENDIX A \\ OTHER SELF-HELP GROUP PROJECTS}

INTRODUCTION

The following projects and organizations were identified as key informants in the area of self-help information and referral service. Their contributions were solicited for their potential assistance and collaboration in the development and operation of SIS and in achieving the overall goals of the research project. Three self-help information and referral services were located: Long Island Self-Help Clearinghouse, New York City Self-Help Clearinghouse, and Westchester Self-Help Clearinghouse. All are located in New York. Other projects were located which publish self-help group directories but none that provide a telephone self-help information and referral service. The three New York clearinghouses utilize a group inventory form and a self-help group typology similar to those employed by SIS. In addition, they are similar to the Self-Help Project in Portland in terms of their approach towards the phenomena of self-help and the scope of their activities. A summary of the responses received by the various projects follows.

\section{TRI-CITY FAMILY PROJECT}

The Tri-City Family Project in Geneva, Illinois periodically publishes a self-help group directory as a newspaper supplement. The directory staff have found that the leadership and contacts of self-help 
groups are too fluid (i.e. change too rapidly) for an annually published directory. The self-help groups are listed under thirteen different rubrics, including adoption, alcohol, consciousness raising, health, etc. In addition, the directory includes a listing of self-help group resources, such as agencies or organizations who offer services to self-help groups and their members.

\section{LONG ISLAND SELF-HELP CLEARINGHOUSE}

\section{Long Island Self-Help Clearinghouse (LISHC) was founded "to}

serve as a locus from which to stimulate links between professional human services and natural support systems." Among the activities of LISHC are catalyzing new self-help groups, providing consultation and education for self-help groups and the community, conducting research of self-help groups, and providing a self-help information and referral system. LISHC constructed a group inventory form to collect specific information about each self-help group participating in their information and referral service. In their search for self-help groups, LISHC used a flexible typology loosely based on Levy's and Gartner and Riessman's work (Levy, 1976; Gartner \& Riessman, 1977). Thus the project's inventory includes some professionally sponsored and/or controlled groups which have components of self or mutual help.

The research goals of LISHC are focused on examining the purposes and functions of self-help groups and their relationships with human service professionals. Additionally, the project's research efforts have included identifying populations with needs capable of being met by self-help groups. The staff of LISHC are involved in facilitating the 
development of social support networks with former in-patients from a state psychiatric facility.

\section{NEW YORK CITY SELF-HELP CLEARINGHOUSE}

The New York City Self-Help Clearinghouse was founded to "organize and disseminate information on the hundreds of self-help mutual aid groups in the five boroughs." Among the many services offered by the Clearinghouse are self-help information and referral, a self-help group directory, a self-help newspaper, a manual entitled "How to Organize a Self-Help Group," and self-help workshops and consultation. The clearinghouse defines a self-help group as a group of persons who share similar problems or concerns and who mutually assist each other with their problems or concerns. The essential ingredient is that the group relies on its members or peers for most of the support in addressing their concerns, but professionals may also be supplementally involved.

The New York City Self-Help Clearinghouse's Directory of SelfHelp Groups has self-help groups categorized under 18 rubrics including addiction, health, mental health, sexuality, and women. The clearinghouse has developed a group information form to collect the information necessary for the directory and the information and referral service. of the mental health groups 1isted, five groups address problems and concerns experienced by the chronically mentally ill and/or their families: Depressives Anonymous, Recovery From Depression, Inc., Emotions Anonymous, Friends and Relatives of the Schizophrenic, and Project Release. In addition to the publication "How to Organize a Self-Help Group," the clearinghouse has also developed a two-page document elaborating the basic issues concerning self-help group formation. The clearinghouse's 
research focus is on the characteristics of the self-help process, the effects of self-help groups on their members, and relationships between self-help groups and professionals.

\section{AMERICAN INSTITUTES FOR RESEARCH}

The Cambridge, Massachusettes branch of the American Institutes for Research (AIR) received a two year grant from the National Institute of Mental Health to develop a project to provide technical assistance to self-help groups serving six specific populations. The project conducted a survey of mutual help groups in the greater Boston area to determine the organizational needs and resources of self-help groups serving the target populations. The project has worked collaboratively with selected groups in developing technical assistance materials which are designed to serve as models for use with other self-help groups. To help facilitate the goals of the study, a review of the literature was conducted focusing on self-help group needs and resources.

\section{PROJECT HOPE-NORTHEASTERN ILLINOIS UNIVERSITY}

Project Hope at Northeastern Illinois University publishes a Directory of Self-Help Groups for Serious and Chronic IIlnesses and Bereavement and collaborates with Leonard Borman, Director of the SelfHelp Institute at Northwestern University's Center for Urban Affairs. The process of locating the information contained in the Directory was assisted by Project Hope participants and by students at the University. The Directory was compiled with the intention of locating as many selfhelp groups as possible in the Chicago area. 
The project states that difficulties arose in locating groups not connected with institutions or other organizations. Further difficulties arose due to confusion over the term "self-help" and the subsequent problems in categorizing which groups are and which are not self-help. The distinction was made by self classification by the representative of the group being interviewed. Groups are classified as "self-help" or as a "resource." A group listed in the resource section is one which states that a professional is actively involved in the group's treatment. The groups are also categorized according to afflictions of organs of the body and psychological condition. In addition to information about selfhelp groups, the directory includes resources of other organizations and a bibliography of appropriate books geared to the layperson.

If persons in the Chicago area cannot find self-help groups to meet their needs, Project Hope or the Self-Help Institute will list their names and put people who want to communicate with others in similar circumstances in contact with each other. The project and institute will also support efforts to launch self-help groups with suggestions and organizational help.

MENTAL HEALTH ASSOCIATION OF SAN FRANCISCO

During 1980 volunteers of the Mental Health Association of San Francisco formed the Self-Help Project to increase the public's awareness of self-help groups, to assist self-help groups requesting aid, and to encourage and assist in the formation of new groups. The Association published a directory of self-help groups in 1980 and publishes a 1ist of revisions and additions to the directory periodically. The Association 
also publishes a newsletter called "The Self-Help News" which serves as a forum to exchange ideas, share experiences, promote activities and celebrate the achievements of self-help group members in the San Francisco area.

FRANKLIN/HAMPSHIRE COMMUNTTY MENTAL HEALTH CENTER-MASS.

The Franklin/Hampshire Community Mental Health Center provides consultation and assistance to self-help groups through its Consultation and Education Team. The Center publishes a directory of self-help groups to make these groups more visible and accessible to those who need them.

$$
\text { SELF-HELP INFORMATION SERVICE-LINCOLN, NEBRASKA }
$$

The SIS in Lincoln gleans most group contact information from notices of meetings in the three local newspapers. The groups are contacted by phone. Groups should be peer, that is composed of people with a common problem,sharing experience, strength, and hope and preferably following national guidelines.

The directory is limited to Lincoln, Nebraska, but consultation is provided to groups throughout the state. Five thousand directories (in brochure form) are distributed free about four times a year. The service is completely volunteer and different agencies donate printing.

\section{WESTCHESTER SELF-HELP CLEARINGHOUSE}

The Westchester Self-Help Clearinghouse is a nonprofit service sponsored by the Westchester County Department of Community Mental Health, Harlem Valley Psychiatric Center, and Pace University. The Clearinghouse was developed in response to a growing need for easier access to self- 
help, mutual aid programs in the Westchester area. The Clearinghouse provides confidential information and referral to self-help group leaders, assists existing self-help groups, and educates the community about how we can help ourselves and each other. Initiated in late 1979, the Clearinghouse is part of the county's overall effort to prevent mental illness by reducing isolation and stress and, at the same time, increasing individual strengths and coping skills.

Self-help is defined in terms of whether or not a fee is charged for services for the purpose of profit-making for an agency or professional. There is not necessarily a distinction made by professionally led vs. non-professionally led groups. Groups that charge a fee for profit are not defined as self-help groups and are not included in the directory, which is a comprehensive list of self-help services.

When people call the Clearinghouse for a referral to a self-help group which does not yet exist in the area, assistance will be provided in forming a new group. The Clearinghouse offers free training for self-help group leaders to teach basic counseling and group leadership skills. The Clearinghouse provides consulting services to existing selfhelp groups and is preparing to offer a free workshop for professionals to teach how professionals can best be involved with self-help groups. The Clearinghouse developed two questionnaires both asking for a brief description of the group, contact persons and telephone numbers, and information about membership. One questionnaire collects information about groups in the area and one about groups outside of the area. The Clearinghouse also compiles a general needs assessment of the types of services that would be useful to the groups in the program. 
1. a. What is the legal name of the group?

b. What is the common name of the group?

c. What are any previous names of the group?

2. Who are two contact persons for the group?

a. Name:

telephone (day)

b. Name: telephone (day) (night) (night)

3. What is the mailing address of the group?

4. What is the purpose of the group?

5. In general, what types of people are in the group? (i.e. age, sex, race, marital status, parental status, occupational status, etc.)

6. MEMBERSHIP PROCESS:

a. Who is eligible to join the group?

b. Is the group accepting new members?

c. Will the group accept referrals from the information and referral service?

d. What is the procedure for becoming a new member?

e. What membership duties are required? dues: attendance: other (please specify)

f. What membership duties are encouraged but not required?

g. Is member participation in the group process required?

h. How long does the average member participate in the group?

7. MEETINGS

a. Are there group meetings which are open to the public? yes If yes; time place

Is the meeting place accessible to the handicapped? yes___no___ By public transportation? yes__no___ Bus number What is the average number of people who at tend a meeting?

What is the total number of members in this group?

b. Are there group meetings which are closed to the public? yes If yes, time ___ place Is the meeting place accessible to the handicapped? yes no By public transportation? yes__no____ Bus number What is the average number of people who attend a meeting? What is the total number of members in this group?

c. Are there group activities outside of scheduled meeting times? If yes, what is the frequency? Purpose?

d. Are group meetings confidential? Exceptions?

e. What is the expected duration of the group? Onguing Time limited (please specify) 
8. SERVICES PROVIDED:

Are any of the following services provided?

SUPPORT
EDUCATION/INFORMATION
CONSULTATION/LIAISON (LINKING)
REFERRAL
THERAPY
PERSONAL GROWTH
OTHER (PLEASE SPECIFY)

ADVOCACY (POLITICAL ACTION)

PHYSICAL ASSISTANCE

MATERIAL ASSISTANCE

RECREATIONAL ACTIVITIES

ACTIVITIES OF DAILY LIVING

PERSONAL/SOCIAL ADJUSTMENT (REHAB)

9. PROFESSIONAL INVOLVEMENT:

a. Are there any professionals involved with the group? yes no

If yes, are professionals involved in any of the following capacities? (please

indicate expected duration of involvement):

LEADER

FACILITATOR

THERAPIST OBSERVER

CONSULTANT

OTHER (PLEASE SPECIFY)

b. Who controls the group? Members

Professionals

Other (please specify)

10. ORGANIZATIONAL STRUCTURE

a. When was the group established?

b. Does the group receive any funds? yes_no_ If yes, please specify

the source(s) of funds:

c. Is the group linked with any other groups, agencies, and/or persons?

If yes, please specify the linkage (affiliation, sponsor, etc.):

d. Does the group fall within any of the following categories:

PUBLIC PRIVATE PROFIT

NON-PROFIT INCORPORATED LICENSED BOARD OF DIR.

e. Does the group have any designated leaders? yes no If yes, are the

leaders elected by the members appointed (if so, by whom)

other (please specify)

f. Does the group publish literature? yes_no_ If yes, how frequently?

Is there a fee?

Would the group please send us copies of any publications to:

RRI, PORTLAND STATE UNIVERSITY, P.O. BOX 751, PORTLAND, OR 97207

g. If the group inftiated contact with SIS, how did the group learn of SIS?

11. PERSONS INTERVIEWED:

Name:

Date interviewed:

by:

Name:

Date interviewed:

by:

12. INTERVIENER CONMENTS: 


\section{TRI-COUNTY COMMUNITY COUNCIL \\ INFORMATION AND REFERRAL SERVICES}

DATE

TELEPHONE

LEGAL NAME OF ORGANIZATION

ABBREVIATED OR COMMON NAME

AFFILIATION

STREET ADDRESS

CITY

ZIP

MAILING ADDRESS

CITY

ZIP

BRANCH ADDRESS (if any)

NAME AND TITLE OF PERSON IN CHARGE

NAME AND TITLE OF CONTACT PERSON

HOURS

SIMAMARY OF SERVICES (please be specific and concise)

\section{ELIGIBILITY CRITERIA}

APPLICATION PROCEDURE

\section{FEES}

CAPACITY (if applicable)

GEOGRAPHIC AREA SERVED

SOURCE OF FUNDING 
NUHEER OF STAFF NUTABER OF VOLUITFERS

TYPE OF ORGANIZATION:

PUBLIC PRIVATE PROFIT NON-PROFIT INCORPORATED

LICEMISED _ COARD OF DIRECTOR.S

PLEASE ANSHER THE FOLLOHING nUUESTIONS:

What is the particular target population served hy your agency? ( e.g.youth, seniors)

How long has the agency/service been in operation?

Is the building in which your service is located harrier-free? (for handicapped Deople)

Is the service accessible by public transportation? If so, please indicate bus line number $(s)$

Are there any interpreter services availatle? If so, what are they? (e.g. Spanish, Vietnamese, sign lanquagge, etc.)

Does your agency or crạnization puhlish a newsletter or distribute literature?

Frequency? Fee?

Is your agency or organization listed in the Tri-County Community Cauncil's Directory of Community Services? In there to Turn?

SIGNATURE

DATE

INTERVIEUED BY :

COANEENTS: 


\section{APPENDIX D}

\section{PROTOCOL FOR USING THE RESOURCE INVENTORY}

Hello. My name is and I'm working with Portland State University and Tri-County Information and Referral to link Self-Help Groups in the community with people interested in joining groups. We'd like to get some information from you specifically about your group so that, if your group wishes, we could let interested callers know more about you. Would you be interested in this?

IF YES, PROCEED WITH INTERVIEW

IF GROUP MEMEER HAS RESERVATIONS, ASK IF WE CAN CALL BACK AFTER THE PERSON DISCUSSES OUR OFFER WITH THE GROUP. PLEASE NOTE STATUS OF THE CALI-BA.CK AND PAPERCLIP TO THE INVENTORY.

IF NO, COULD WE ASK SOME QUESTIONS ABOUT YOUR GROUP--WE'D KEEP THE INFORMATION CONFIDENTIAL AND WIIL USE IT SOLELY FOR OUR FILES.

NOTE: If questions arise as to the nature or definition of a self-help group, refer to the following definition:

A Self-Help Group is an interacting face-to-face group...

1) whose members experience a sense of group identity related to their cormon core of life experiences and concerns.

2) whose members exchange helping (efforts, skills, knowledge and concerns) based on the belief of peers as a primary source of help.

3) whose members, rather than professionals or agencies have control over the group itself.

4) whose sanction for existence rests with the members themselves rather than an external agency or authority.

Questions for testing control (\#3) and sanction (\#4) would be: If the professional withdrew, would the group disband? If funding was withdrawn would the group disband?)

**ILEAVE THE PORTION OF THE FORM ABOVE THE ASTERISKS BLANK; START THE INTERVIEW WITH QUESTION \#1.

\#1) Proceed through parts (a) (b) \& (c).

\#2) Obtain as many contact names and telephone numbers for each group as possible. Use extra lines under \#12, Interviewer comments-on the reverse side, if necessary. **Ask the contact person to call us if there are any changes in group or contact person information.

\#3) If there is any question or confusion arising from the use of several different addresses, ask, "What is the best place to send mail to the group?".

\#4) Proceed.

\#5) Proceed with this question probing for the characteristics listed.

\#6) (a) Find out who is eligible to join, but also probe for restrictions regarding who can not join the group.

(b) -- (h) Proceed.

(a) -- (e) Proceed. 
\#8) THE SERVICES ARE DEFINED BELOW:

SUPPORT: the offering of emotional comfort, reassurance, or strengthening gestures including the cultivation of a sense of belonging or community.

EDUCATION/INFORMATION: the dissemination of knowledge or information. CONSULTATION: meeting to examine a concern and share ideas.

REFERPAL: the linking of a person with needs to the resources capable of meeting the needs.

THERAPY: actions intended to alleviate or reverse a person's problem or concern by increasing his or her coping ability.

PERSONAL GROWIH: activities intended to enhance the quality of a person's own life.

ADVOCACY: to plead or press a cause on behalf of one or more individuals to a group or organization.

PHYSICAL ASSISTANCE: the provision of bodily help (i.e. sharing rides, pushing wheelchairs, baby-sitting, etc.).

MATERIAL ASSISTANCE: the provision of goods and/or money (i.e. sharing or trading clothes, books, tools, money, etc.).

RECREATIONAL ACTIVITIES: gathering together for the purpose of play, amusement and/or relaxation inside or outside of the scheduled group meeting time.

ACTIVIIIES OF DAILY LIVING: training of individuals to acquire skills in independent living (habilitation).

PERSONAL/SOCIAL ADUUSTMENT: training persons to facilitate their functioning within the limits of a disability or to regain skills lost due to a disability (rehabilitation).

\#9) Proceed.

\#10) (a) \& (b) Proceed.

(c) When asking about linkage and affiliation, probe also for religious orientation.

(d) THE CATECORIES ARE DEFINED BEIOW: PUBLIC: primarily funded by the government

PRTVATE: not funded by the government

PROFIT: money-making organization-no restrictions on profit accumulation NON-PROFIT: legally, must return excess money to its programs INCORPORATED: a legally recognized entity LICENSED: officially licensed

(e) Proceed.

(f) Ask for copies if there is no charge.

(g) Proceed.

\#11) Proceed.

\#12) Please add any thoughts or comments you may have about the interview or the group.

\section{EURTHER INSTRUCTIONS:}

Please do not define services unless specifically asked for such information; it is best to let the group member describe the services of his/her group and then fit that information into categories on the resource inventory.

collect information on all groups that have some self-help components, even if the group does not meet all the criteria under the given self-help group definition. 
APPENDIX E

CODING

A multi-dimensional coding system was developed by Project staff since a unidimensional coding of concern could not accurately describe and categorize the vast number and types of groups that were to be classified.

The major features of the coding system are concern, role and function. The concerns are clustered under the broad categories of violence, health and mental health, life status, personal growth/ cultural adaptation, religion, co-ops, politics and other. Other self-help group features were also coded--each group was described as either a pure self-help group, a mixed group (some selfhelp components and some not self-help components), not a self-help group or other type of group. The location of the group meeting place is an important determinant of member accessibility and was coded by the quadrant of the meeting place.

Each group is assigned an identifying number which is entered on a master list--the groups are numbered as they are contacted. As of this writing there are 136 groups listed with SIS. 


\section{APPENDIX F}

\section{POTENTIAL MEMBER RESOURCE INVENTORY}

FETRENCE NUNBER

Note: When returning calls to rotential group members, do not leave messages from the "Self-Heln Project" which may cause embarrassment.

\section{FCTENTIAL MDPBR INTERVIEVI}

1. What is your name?

2. Telephone (hame) (work)

3. Address

4. What is your concern? (i.e. What type of group are you interested ir:?)

5. Are there any special circumstances which might affect your participation in a group (i.e. physical handicap, etc.)?

**Refer to the file of available self-help groups and see if there is an aporopriate group to meet the caller's reed(s). If there is a croun available, make the referral and proceed with question 7; if there is no group available proceed with cquestion 6. (Note referral and date under Status of Indiv. Contact kelow).

6. If there is no Self-Hielp Group to fit the caller's need, ask: "Hould you be willing to be on a waiting list to form a group"? "Would you be willing to help launch the group"?

7. Explain that the following information is optional and for our book-keeping and filing purposes only:

a. What is your age?

What is your sex?

What is your Ethnic I.D.?

Are you enployed? yes no

If yes, what is your cccupation?

b. If the potential member contacted us, ask:

"How did you leam of the Self-Help Information Service?"
Living Situation:

Indivicual

Counole

Single Parent

Two Parent

Number of Children

ITTEFVIEWED BY: DATE

INTERVIEWER COMMENTS: 


\section{APPENDIX G}

\section{SELF-HELP PROJECT STAFF RESPONSES TO THE SIS EVALUATION QUESTIONNAIRE}

This section includes the questions and responses of the Self-Help Project staff to the Self-Help Information Service. The mission of the Self-Help Information Service was summarized as being the expansion of the quality and scope of human services available to meet community members' needs. Specifically, the goals of the Self-Help Information Service (SIS) were described as being to search out and inventory all self-help groups in the Tri-County area and to link potential members in the community with the appropriate self-help groups available to meet those needs. The Self-Help Project staff were asked to evaluate their involvement in three aspects of SIS: (a) the Self-Help Group Inventory, (b) the potential member inventory, and (c) the information campaign. The initial portion of the questionnaire encompassed three parallel sections for each of the three aspects. Note, since the $\mathrm{N}=10$ for this population, frequencies only (and not proportions) are given. Also note that the numbering system parallels that used on the actual questionnaire (see Appendix K) I.Al Inventory of Self-Help Groups--Project staff were asked how many hours per week for the last four months they worked on locating selfhelp groups and collecting information for the Self-Help Group Inventory form. The total number of responses was ten. One staff spent five hours per week, one spent four hours per week, four spent three hours per week, 
one spent two hours per week, one spent one hour per week, and two spent zero hours per week working on the inventory in the last four months.

\section{TABLE I}

STAFF TIME WORKING ON THE GROUP INVENTORY

\section{Response}

Frequency

Worked $5 \mathrm{hrs} / \mathrm{wk}$ on Inventory of SHG's over last 4 months Worked $4 \mathrm{hrs} / \mathrm{wk}$ on Inventory of SHG's over last 4 months Worked $3 \mathrm{hrs} / \mathrm{wk}$ on Inventory of SHG's over last 4 months Worked $2 \mathrm{hrs} / \mathrm{wk}$ on Inventory of SHG's over last 4 months Worked $1 \mathrm{hr} / \mathrm{wk}$ on Inventory of SHG's over last 4 months Worked $0 \mathrm{hrs} / \mathrm{wk}$ on Inventory of SHG's over last 4 months Tota1 10

I.A2 Question two asks how satisfactory the amount of time working on the Self-Help Group Inventory has been for each staff member. The total number of responses was ten. Seven responded that the amount of time was "very satisfactory," three responded that it was "satisfactory," none responded that it was "unsatisfactory," and none responded that it was "very unsatisfactory."

\section{TABLE II}

STAFF SATISFACTION WITH TIME SPENT ON THE GROUP INVENTORY

\begin{tabular}{lc}
\hline \multicolumn{1}{c}{ Response } & Frequency \\
\hline & 3 \\
Very satisfactory & 7 \\
Satisfactory & 0 \\
Unsatisfactory & 0 \\
Very Unsatisfactory & 10 \\
\hline Total & 10 \\
\hline
\end{tabular}


I.A3 Question three probed for the reasons for an unsatisfactory response to the amount of time working on the Self-Help Group Inventory. No responses.

I.A4 Question four asks for staff opinions regarding how useful the Self-Help Group Inventory form is for compiling facts necessary for the project. The total number of responses was ten. Seven responded that it was "very useful," and one responded that it was "useful," none responded that it was "not useful," and two responded that they "did not know."

TABLE III

USEFULNESS OF THE INVENTORY FORM

\begin{tabular}{lc}
\hline Response & Frequency \\
\hline Very useful & 7 \\
Useful & 1 \\
Not useful & 0 \\
Don't know & 2 \\
\hline Total & 10 \\
\hline
\end{tabular}

I.A5 Question five asks for staff opinions regarding the SelfHelp Group Inventory procedures or protocol. The total number of responses was ten. Two thought the procedures were "cumbersome," seven thought they were "adequate and comprehensive," none thought they were "sketchy and inadequate," and one "did not know." 
TABLE IV

STAFF OPINION OF GROUP

INVENTORY PROCEDURES

\begin{tabular}{ll}
\hline \multicolumn{1}{c}{ Response } & Frequency \\
\hline & 2 \\
Cumbersome & 7 \\
Adequate and comprehensive & 0 \\
Sketchy and inadequate & 1 \\
Don't know & 10 \\
\hline Total & \\
\hline
\end{tabular}

I.A6 Question six asks staff opinion regarding whether they received clear directions for using the Self-Help Group Inventory. The total number of responses was ten. Seven responded "yes," one responded "no," none responded "somewhat," and two responded "not applicable."

TABLE V

CLARITY OF GROUP INVENTORY

DIRECTIONS

\begin{tabular}{lc}
\hline \multicolumn{1}{c}{ Response } & Frequency \\
\hline Yes & 7 \\
No & 1 \\
Somewhat & 0 \\
Not Applicable & 2 \\
\hline Total & 10 \\
\hline
\end{tabular}

I.A7 Question seven asks for staff feelings in contacting self-help groups to inventory. The total number of responses was ten. Six responded "yes" they were comfortable, one responded "no," two responded "somewhat," and one responded that the question was "not applicable." 
TABLE VI

STAFF COMFORT CONTACTING

GROUPS

\begin{tabular}{lc}
\hline \multicolumn{1}{c}{ Response } & Frequency \\
\hline Yes & 6 \\
No & 1 \\
Somewhat & 2 \\
Not applicable & 1 \\
\hline Total & 10 \\
\hline
\end{tabular}

There were three responses to an open-ended question probing for the reasons for not being comfortable contacting self-help groups to inventory. Two of the respondents mentioned that they felt it took too much of the group member's time. One response was simply that it was not the staff person's job. Other responses included lacking adequate knowledge to answer contact questions about SIS, that the questionnaire is repetitious, and that group contacts offer more information than there is room for on the questionnaire.

I.B1 Potential Member Inventory--Project staff were asked how many hours per week they worked contacting potential members and filling out Potential Member Inventory forms. The total number of responses was ten. Three staff spent four hours per week in the last four months, one staff person spent three hours per week, no staff person spent two hours per week, two staff persons spent one hour per week and four staff spent zero hours per week. 
TABLE VII

STAFF TIME WORKING ON THE POTENTIAL MEMBER INVENTORY

Response

Worked $4 \mathrm{hrs} / \mathrm{wk}$ on Member Inventory over last 4 months Worked $3 \mathrm{hrs} / \mathrm{wk}$ on Member Inventory over last 4 months Worked $2 \mathrm{hrs} / \mathrm{wk}$ on Member Inventory over last 4 months Worked $1 \mathrm{hr} / \mathrm{wk}$ on Member Inventory over last 4 months Worked $0 \mathrm{hrs} / \mathrm{wk}$ on Member Inventory over last 4 months Tota1

\section{Frequency}

3

1

0

2

4

I.B2 Question two probes staff opinion about how satisfactory the amount of time worked on the potential member questionnaire was for each staff member. The total number of responses was ten. Six responded that the amount of time was "very satisfactory," three responded that the amount of time was "satisfactory," and one responded that he/she "did not know."

TABLE VIII

STAFF SATISFACTION WITH TIME

SPENT ON POTENTIAL

MEMBER INVENTORY

\begin{tabular}{lc}
\hline \multicolumn{1}{c}{ Response } & Frequency \\
\hline & \\
Very satisfactory & 6 \\
Satisfactory & 3 \\
Unsatisfactory & 0 \\
Very unsatisfactory & 0 \\
Don't know & 1 \\
\hline Total & 10 \\
\hline
\end{tabular}

I.B3 Question three probed for reasons that the amount of time was unsatisfactory. No responses. 
I.B4 Question four probes for staff opinion regarding the usefulness of the Potential Member Questionnaire in capturing the needed facts. The total number of responses was ten. Six responded "very useful," two responded "useful," and two responded "don't know."

TABLE IX

USEFULNESS OF THE POTENTIAL MEMBER QUESTIONNAIRE

\begin{tabular}{lc}
\hline Response & Frequency \\
\hline Very useful & 6 \\
Useful & 2 \\
Not useful & 0 \\
Don't know & 2 \\
\hline Total & 10 \\
\hline
\end{tabular}

I.B5 Question five asks staff opinion regarding the adequacy of the procedures for using the Potential Member Questionnaire. The total number of responses was ten. Six responded that the procedures were "comprehensive and adequate," two that the procedures were "sketchy and inadequate," and two "did not know."

TABLE X

STAFF OPINION OF POTENTIAL MEMBER INVENTORY PROCEDURES

Response

Cumbersome

Adequate and comprehensive

Sketchy and inadequate

Don't know

Total

\section{Frequency}

0

6

2

2 
I.B6 Question six asks for staff opinion regarding the clarity of the directions given to them for utilizing the Potential Member Questionnaire. The total number of responses was ten. Seven responded "yes," one responded "no," and two responded "not applicable."

TABLE XI

CLARITY OF POTENTIAL MEMBER INVENTORY DIRECTIONS

\begin{tabular}{lc}
\hline \multicolumn{1}{c}{ Response } & Frequency \\
\hline & \\
Yes & 7 \\
No & 1 \\
Somewhat & 0 \\
Not Applicable & 2 \\
\hline Total & 10 \\
\hline
\end{tabular}

I.B7 Question seven asks how comfortable each staff person is contacting potential members. The total number of responses was ten. Nine responded "yes" they were comfortable and one responded "no."

TABLE XII

STAFF COMFORT CONTACTING POTENTIAL MEMBERS

\begin{tabular}{lc}
\hline Response & Frequency \\
\hline Yes & 9 \\
No & 1 \\
Somewhat & 0 \\
\hline \hline Total & 10 \\
\hline
\end{tabular}

I.C1 Information Campaign--Project staff were asked how many hours per week they worked on the information campaign, i.e. delivering posters, sending press releases, etc., in the last four months. The total number of responses was ten. One of the staff spent six hours per week, two staff 
spent four hours, one staff spent two and one-half hours, one staff spent one and one-half hours, four staff spent one hour, and one staff spent zero hours.

TABLE XIII

STAFF TIME WORKING ON THE INFORMATION CAMPAIGN

Response

Frequency

Worked $6 \mathrm{hrs} / \mathrm{wk}$ on Information Campaign in last 4 months 1

Worked $5 \mathrm{hrs} / \mathrm{wk}$ on Information Campaign in last 4 months 0

Worked $4 \mathrm{hrs} /$ wk on Information Campaign in last 4 months 2

Worked $3 \mathrm{hrs} / \mathrm{wk}$ on Information Campaign in last 4 months 1

Worked $2 \mathrm{hrs} / \mathrm{wk}$ on Information Campaign in last 4 months 1

Worked $1 \mathrm{hr} /$ wk on Information Campaign in last 4 months 4

Worked $0 \mathrm{hrs} / \mathrm{wk}$ on Information Campaign in last 4 months 1

\begin{tabular}{ll}
\hline Total & 10
\end{tabular}

I.C2 Question two asks for staff opinion regarding how satisfactory the amount of time spent on the information campaign was. The total number of responses was ten. Three responded that this amount of time was "very satisfactory," six responded "satisfactory," one responded that it was

"unsatisfactory."

TABLE XIV

STAFF SATISFACTION WITH TIME SPENT

ON THE INFORMATION CAMPAIGN

\begin{tabular}{lc}
\hline \multicolumn{1}{c}{ Response } & Frequency \\
\hline & \\
Very Satisfactory & 3 \\
Satisfactory & 6 \\
Unsatisfactory & 1 \\
Very unsatisfactory & 0 \\
\hline Total & 10 \\
\hline
\end{tabular}


I.C3 Question three probed for reasons for dissatisfaction. There was one response total that mentioned that the poster delivery took too long and involved too much person power and was not a good use of the Project Director's time.

I.C4 Question four asks for staff opinion regarding how useful the SIS poster is for conveying the needed facts. The total number of responses was ten. Four responsed "very useful," and six responded "useful."

TABLE XV

USEFULNESS OF POSTER IN CONVEYING NECESSARY INFORMATION

\begin{tabular}{lc}
\hline Response & Frequency \\
\hline & \\
Very useful & 4 \\
Useful & 6 \\
Not useful & 0 \\
Don't know & 0 \\
\hline Total & 10 \\
\hline
\end{tabular}

I.C5 Question five asks for staff opinion regarding the campaign procedures. The total number of responses was ten. Six responded that the procedures were "adequate and comprehensive," two responded "sketchy and inadequate," and two responded "don't know."

TABLE XVI

STAFF OPINION OF INFORMATION

CAMPAIGN PROCEDURES

\begin{tabular}{lc}
\hline \multicolumn{1}{c}{ Response } & Frequency \\
\hline & \\
Cumbersome & 0 \\
Adequate and comprehensive & 6 \\
Sketchy and inadequate & 2 \\
Don't know & 2 \\
\hline Total & 10 \\
\hline
\end{tabular}


I.C6 Question six asked for staff opinion on the clarity of the directions received for the information campaign. The total number of responses was ten. Seven responded "yes" that the directions were clear, two responded "no," and one responded "not applicable."

TABLE XVII

CLARITY OF DIRECTIONS FOR INFORMATION CAMPAIGN

\begin{tabular}{lc}
\hline \multicolumn{1}{c}{ Response } & Frequency \\
\hline Yes & 7 \\
No & 2 \\
Somewhat & 0 \\
Not applicable & 1 \\
\hline Total & 10 \\
\hline
\end{tabular}

I.C7 Question seven asked how comfortable each staff member was disseminating information about SIS. The total number of responses was ten. Eight responded "yes" they were comfortable, one responded "no," and one responded "somewhat."

TABLE XVIII

STAFF COMFORT DISSEMINATING

SIS INFORMATION

\begin{tabular}{lc}
\hline Response & Frequency \\
\hline Yes & 8 \\
No & 1 \\
Somewhat & 1 \\
\hline Total & 10 \\
\hline
\end{tabular}

There were two responses regarding reasons for discomfort: one response was "no time to do it," and another response was "I felt like a salesman." 
II.A There were ten responses to the question of satisfaction regarding the way SIS handles referrals in general. Three responded "very satisfied," five responded "satisfied," one responded "dissatisfied," and one responded "don't know."

TABLE XIX

SATISFACTION WITH REFERRAL PROCEDURES

\begin{tabular}{lc}
\hline \multicolumn{1}{c}{ Response } & Frequency \\
\hline & \\
Very satisfied & 3 \\
Satisfied & 5 \\
Dissatisfied & 1 \\
Very dissatisfied & 0 \\
Don't know & 1 \\
\hline Total & 10 \\
\hline
\end{tabular}

II.B There were four responses to the question of how the handing of referrals might be improved. Two responded that there was too long a call back time or inconsistent call back procedures. Additionally, there was one response for "more publicity and public relations," for a "more comprehensive filing system," and for "better coordination with Tri-County Information and Referral."

III. The third section summarized the collaborative relationship that exists between the Self-Help Project and Tri-County Information and Referral. The Self-Help Project used Tri-County's resource inventory and expertise in the inventory of self-help groups. Tri-County $I \& R$ also provides a 40 hour per week telephone service to collect and disseminate information for SIS. In return, the Self-Help Project provides 16 to 24 hours of "volunteer" time to staff Tri-County's phones.

III.A Self-Help staff were probed as to how many hours per week they spend at Tri-County $I \& R$. The total number of responses was ten. Five 
responded that they spent between four and six hours per week, two spent between one and three hours per week, and three spent zero hours per week.

TABLE XX

STAFF TIME SPENT AT TRI-COUNTY I \& R

4-6 hr/wk spent at Tri-County I \& $\mathrm{R}$ in last 4 months 5 1-3 hr/wk spent at Tri-County $I$ \& $R$ in last 4 months 2 $0 \mathrm{hr} / \mathrm{wk}$ spent at $\operatorname{Tr} \mathrm{i}$-County $\mathrm{I} \& \mathrm{R}$ in last 4 months Total 10

III.B Self-Help staff were asked how satisfactory this arrangement (i.e. time spent at $I \& R$ ) was to them. Of ten responses, six responded "very satisfactory," three responded "satisfactory," and one responded "less than satisfactory."

TABLE XXI

STAFF SATISFACTION WITH TIME

SPENT AT TRI-COUNTY I \& $R$

\begin{tabular}{lc}
\hline \multicolumn{1}{c}{ Response } & Frequency \\
\hline & \\
Very satisfactory & 6 \\
Satisfactory & 3 \\
Less than satisfactory & 1 \\
Very unsatisfactory & 0 \\
Not applicable & 0 \\
\hline Total & 10 \\
\hline
\end{tabular}

III.C of the ten responses regarding how satisfactory the training was for work at $I \& R$, three Self-Help staff responded "very satisfactory," four responded "satisfactory," one responded "unsatisfactory," and two responded "not applicable." 
TABLE XXII

STAFF SATISFACTION WITH

I \& $\mathrm{R}$ TRAINING

\begin{tabular}{lc}
\hline \multicolumn{1}{c}{ Response } & Frequency \\
\hline Very satisfactory & 3 \\
Satisfactory & 4 \\
Unsatisfactory & 1 \\
Very unsatisfactory & 0 \\
Not applicable & 2 \\
\hline Total & 10 \\
\hline
\end{tabular}

IV.A Self-Help Project staff were probed as to how the attitudes of other Self-Help Project staff towards them, as a co-worker, have been. Of the ten responses, seven responded "very satisfactory," two responded "satisfactory," and one responded "less than satisfactory."

TABLE XXIII

ATTITUDES OF OTHER SELF-HELP

PROJECT STAFF

\begin{tabular}{lc}
\hline \multicolumn{1}{c}{ Response } & Frequency \\
\hline & 7 \\
Very satisfactory & 2 \\
Satisfactory & 1 \\
Less than satisfactory & 0 \\
Very unsatisfactory & 10 \\
\hline Total
\end{tabular}

IV.B Six Self-Help staff responded that the attitudes of the I \& $R$ staff towards them, as a co-worker, have been "very satisfactory," three responded "satisfactory," and one responded "unsatisfactory," for a total of ten responses. 
TABLE XXIV

ATTITUDES OF TRI-COUNTY

$I \& R$ STAFF

\begin{tabular}{lc}
\hline \multicolumn{1}{c}{ Response } & Frequency \\
\hline Very satisfactory & 6 \\
Satisfactory & 3 \\
Unsatisfactory & 1 \\
Very unsatisfactory & 0 \\
Don't know & 0 \\
Not applicable & 0 \\
\hline Total & 10 \\
\hline
\end{tabular}

V.A Overall, the Self-Help Project staff were probed regarding their satisfaction with SIS. Of the ten total responses, five were "very satisfied," and five were "satisfied."

TABLE XXV

OVERALL STAFF SATISFACTION

WITH SIS

\begin{tabular}{lc}
\hline \multicolumn{1}{c}{ Response } & Frequency \\
\hline Very satisfied & 5 \\
Satisfied & 5 \\
Dissatisfied & 0 \\
Very dissatisfied & 0 \\
Don't know & 0 \\
\hline Total & 10 \\
\hline
\end{tabular}

V.B There was a total of nine responses to the question of what would make the staff more satisfied with the Self-Help Service. Three respondents saw a need for more efficient potential member procedures and systems, three responses mentioned a need for a greater publicity and public relations campaign for SIS, two respondents wanted to see less Self-Help Project staff time at $I \& R$ and more on the Self-Help Project, two respondents suggested a need for better collaboration and cooperation 
between $I \& R$ and the Self-Help Project; one respondent thought that better management of students and their tasks would be beneficial; another response mentioned the need for better communication and information flow between Self-Help Project staff; one respondent desired more Self-Help Project staff time available for the operation of SIS; and one respondent thought there was too long a time lag for students starting their tasks.

VI.Al The Principal Investigator was probed regarding his evaluation of whether SIS was meeting his expectations as conceived of in the grant. The response was that SIS was "more than fulfilling expectations."

VI.B1 The Project Director was probed for satisfaction with SIS in regard to the overall goals of SIS and specifically regarding the coordination of staff time and energy in meeting those goals. The Director's response was that she was "very satisfied" with the proportion of staff time and energy invested in SIS.

VI.B2 When probed about how staff time and energy might be improved in terms of effectiveness, the Director had the following suggestions: have at least one person oversee SIS and have particular individuals responsible for particular parts of SIS, systematize SIS tasks, have students commit evening hours to SIS, have built-in quality checks in the operation of SIS, mail the remaining posters out, and coalesce SIS procedures into written statements.

VI.B3 The director responded that SIS was "very useful" in furthering the attainment of overall research goals by "facilitating contact between Project staff, self-help groups, and potential group members." However, she also felt that greater volume (i.e. more groups and potential members) is needed. 
VI.C1 The students involved in the operation of SIS were asked how useful their involvement with the Self-Help Information Service has been toward expanding their knowledge of basic research and self-help groups in general. Of the four total responses, two responded "very useful," one responded "somewhat useful," and one responded "not useful."

TABLE XXVI

STUDENT OPINION OF INVOLVEMENT

WITH SIS

\begin{tabular}{lc}
\hline \multicolumn{1}{c}{ Response } & Frequency \\
\hline Very useful & 2 \\
Somewhat useful & 1 \\
Not useful & 1 \\
Don't know & 0 \\
\hline Total & 4 \\
\hline
\end{tabular}

VI.C2 There was one response regarding how to improve student experience with the project. The response included having structured orientation sessions on the project and about self-help groups and more opportunities to consult with other project staff.

VI.D1 The Research Assistants were probed as to how useful their involvement with SIS has been in providing work experience useful for professional advancement. Of the four total responses, all responded that involvement with SIS was a "very useful" experience.

TABLE XXVII

RESEARCH ASSISTANT OPINION OF INVOLVEMENT WITH SIS

\begin{tabular}{lc}
\hline \multicolumn{1}{c}{ Response } & Frequency \\
\hline & \\
Very useful & 4 \\
Somewhat useful & 0 \\
Not useful & 0 \\
Don't know & 0 \\
\hline Total & 4 \\
\hline
\end{tabular}


APPENDIX H

DESCRIPTION OF I \& R STAFF QUESTIONNAIRE RESULTS

1A) This question was designed to "test" the knowledge of the staff regarding the appropriate use of the Potential Member form. The worker was asked to describe the procedures for the use of the form for two different instances: a) when a self-help group is available for referral and b) when a self-help group is not available for referral. The following table gives responses for situation a:

TABLE XXVIII

PROCEDURES WHEN A GROUP IS AVAILABLE FOR REFERRAL

\begin{tabular}{lc}
\hline \multicolumn{1}{c}{ Response } & Frequency \\
\hline & 5 \\
Make referral & 0 \\
Explain about evaluation of SIS & 1 \\
Fill out Yellow Sheet & 1 \\
Note referral made on Yellow Sheet & 2 \\
Place in box for pick-up & 9 \\
\hline
\end{tabular}

One worker (1/6) felt it was not applicable for her to know this information, so the total in any category could not exceed five.

The following table gives responses for situation $b$, when a group is not available for referral: 
TABLE XXIX

PROCEDURES WHEN A GROUP IS NOT AVAILABLE FOR REFERRAL

Response

Frequency

Explain that SIS will recontact $w / i$ one week 2

Fill out Yellow Sheet

5

Place in box for pick-up

5

Total

12

1B) The worker is asked if clear directions and/or training were given to work with the Potential Member forms.

TABLE XXX

WORKER TRAINING TO USE POTENTIAL MEMBER FORMS

\begin{tabular}{lc}
\hline \multicolumn{1}{c}{ Response } & Frequency \\
\hline Yes & 1 \\
No & 0 \\
Somewhat & 2 \\
Not Applicable & 3 \\
\hline Total & 6 \\
\hline
\end{tabular}

1C) The worker is asked if she is comfortable responding to Potential Member telephone calls asking for a referral or for further information about the Self-Help Information Service. 
TABLE XXXI

WORKERS COMFORTABLE RESPONDING TO

POTENTIAL MEMBER REQUESTS

FOR FURTHER INFORMATION

\begin{tabular}{lc}
\hline \multicolumn{1}{c}{ Response } & Frequency \\
\hline & \\
Yes & 3 \\
Somewhat & 2 \\
No & 0 \\
Not Applicable & 1 \\
\hline Total & 6 \\
\hline
\end{tabular}

1D) This question asks the worker to describe the procedures for handling Potential Member calls in terms of "interference" with on-line functioning.

TABLE XXXII

HOW POTENTIAL MEMBER PROCEDURES AFFECT ON-LINE FUNCTIONING

\begin{tabular}{lc}
\hline \multicolumn{1}{c}{ Response } & Frequency \\
\hline & \\
Cumbersome & 2 \\
Comprehensive \& Adequate & 2 \\
Sketchy and Inadequate & 0 \\
Not Available & 2 \\
\hline Total & 6 \\
\hline
\end{tabular}

1E) This question is open-ended and asks how might the Potential Member procedures be improved. The three people (1/2) who responded all wanted to limit the data collected on the Yellow Sheet to name, telephone number and concern as time and tact limit their ability to get all the desired information at the time of initial contact. All three respondents felt the Self-Help Project staff could get the rest of the information on the Yellow Sheet at the time of recontact. 
2A) This question was designed to "assess" the knowledge of the staff regarding the intended use of the Group Inventory Form. The worker was asked to describe the procedures for use of the form.

TABLE XXXIII

PROCEDURES FOR USE OF THE GROUP INVENTORY FORM

Response

Frequency

1. The purpose of SIS:

a. Linking function

b. Explain SIS will recontact $w / i$ one week

2. Fill out the appropriate spaces on the white form

3. P1ace in box for pick-up

Total

3

1

4

3

Two people (1/3) felt it was not applicable for them to know this information so the total in any response category could not exceed 4 .

2B) This question asks if the worker was given clear direction and/or training to work with the Group Inventory forms.

TABLE XXXIV

WORKER TRAINING TO USE GROUP INVENTORY FORMS

\begin{tabular}{lc}
\hline \multicolumn{1}{c}{ Response } & Frequency \\
\hline & \\
Yes & 1 \\
No & 2 \\
Somewhat & 2 \\
Not Applicable & 1 \\
\hline \multicolumn{2}{|l}{ Total } \\
\hline
\end{tabular}


2C) This question asks if the worker is comfortable responding to telephone calls from Self-Help Group members -- asking to register their group with SIS or for further information about SIS.

TABLE XXXV

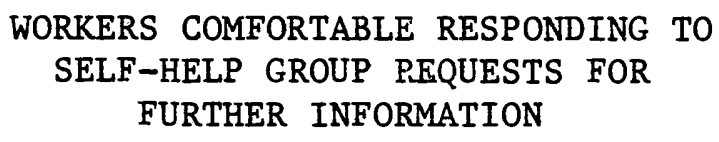

\begin{tabular}{lc}
\hline \multicolumn{1}{c}{ Response } & Frequency \\
\hline Yes & 5 \\
No & 0 \\
Somewhat & 0 \\
Not Applicable & 1 \\
\hline Total & 6 \\
\hline
\end{tabular}

2D) The worker is asked to describe the procedures for handling Group Inventory contacts in terms of interference with on-line functioning.

TABLE XXXVI

HOW GROUP INVENTORY PROCEDURES AFFECT ON-LINE FUNCTIONING

\begin{tabular}{lc}
\hline \multicolumn{1}{c}{ Response } & Frequency \\
\hline & \\
Cumbersome & 2 \\
Comprehensive \& adequate & 3 \\
Sketchy \& inadequate & 0 \\
Not Applicable & 1 \\
\hline Total & 6 \\
\hline
\end{tabular}

2E) This question is open-ended and asks how might the Group Inventory procedures be improved. One person (1/6) responded recommending that inventory procedures be incorporated into the data collection and file updating system of Tri-County I \& $R$. 
3A) This question asks if referrals are made promptly to potential members when a group is available.

TABLE XXXVII

HOW OFTEN REFERRALS ARE MADE PROMPTLY WHEN A GROUP IS AVAILABLE

\begin{tabular}{lc}
\hline \multicolumn{1}{c}{ Response } & Frequency \\
\hline & \\
A1l of the time & 4 \\
Most of the time & 1 \\
Some of the time & 0 \\
Never & 0 \\
Don't know & 0 \\
Not applicable & 1 \\
\hline Total & 6 \\
\hline
\end{tabular}

This question also asks if the referrals are appropriate.

TABLE XXXVIII

HOW OFTEN REFERRALS MADE ARE APPROPRIATE

\begin{tabular}{ll}
\hline \multicolumn{1}{c}{ Response } & Frequency \\
\hline All of the time & 1 \\
Most of the time & 2 \\
Some of the time & 1 \\
Never & 0 \\
Don't know & 1 \\
Not applicable & 1 \\
\hline Table & 6 \\
\hline
\end{tabular}

3B) This question asks if the worker is satisfied with the way the Self-Help Information Service handles referrals when a group is not available for referral to the caller and the contact information is sent to the SIS staff. 
TABLE XXXIX

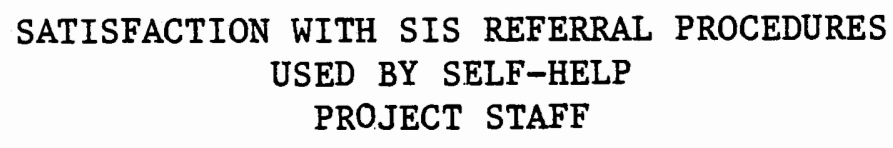

\begin{tabular}{lc}
\hline \multicolumn{1}{c}{ Response } & Frequency \\
\hline Very satisfied & 0 \\
Satisfied & 0 \\
Less than satisfied & 0 \\
Don't know & 5 \\
Not applicable & 1 \\
\hline Total & 6 \\
\hline
\end{tabular}

This question also asks an open-ended question eliciting information about how the handling of referrals might be improved. The two workers (1/3) who responded both suggested that feedback to I \& R would be helpful. Specifically suggested were to let $I \& R$ know when call-back was made and to let I \& $R$ workers know what action (referral) was made with the potential member.

4A) This question asks if $I \& R$ has any written material incorporating the Self-Help Information procedures into the more general Information and Referral procudures.

TABLE XL

WORKERS HAVING KNOWLEDGE OF WRITTEN I \& $R$

PROCEDURES INCORPORATING SIS

INTO I \& $R$

\begin{tabular}{lc}
\hline Response & Frequency \\
\hline Yes & 0 \\
No & 6 \\
Don't Know & 0 \\
\hline Total & 6 \\
\hline
\end{tabular}


4B) This question asks if the worker has a picture of the total system of the Self-Help Information Service, such as where the forms go and when and how the forms are used.

TABLE XLI

WORKERS HAVING A PICTURE OF THE TOTAL SYSTEM OF SIS

\begin{tabular}{lc}
\hline \multicolumn{1}{c}{ Response } & Frequency \\
\hline Yes & 1 \\
No & 4 \\
Somewhat & 1 \\
Not applicable & 0 \\
\hline Total & 6 \\
\hline
\end{tabular}

4C) This question continues that if the worker does not have a picture of the total system would the worker find orientation designed to give that view helpful.

TABLE XLII

ORIENTATION NEEDED TO GIVE A VIEW

OF THE TOTAL SYSTEM

\begin{tabular}{lc}
\hline \multicolumn{1}{c}{ Response } & Frequency \\
\hline & \\
Yes & 5 \\
No & 1 \\
Somewhat & 0 \\
Not applicable & 0 \\
\hline TotaI & 6 \\
\hline
\end{tabular}

4D) This question looks for information about how SIS procedures have impacted day-to-day on-line functioning. 
TABLE XLIII

IMPACT OF SIS ON DAY-TO-DAY ON-LINE FUNCTIONING

\begin{tabular}{|c|c|}
\hline Response & Frequency \\
\hline Disruptive & 0 \\
\hline Smooth & 4 \\
\hline Facilitative & 2 \\
\hline Total & 6 \\
\hline
\end{tabular}

5) This question asks how satisfied $I \& R$ workers are with the collaborative (exchange) arrangement with SIS staff.

TABLE XLIV

SATISFACTION WITH COLLABORATION BETWEEN SIS AND I \& R

\begin{tabular}{lc}
\hline \multicolumn{1}{c}{ Response } & Frequency \\
\hline & \\
Very satisfactory & 5 \\
Satisfactory & 1 \\
Unsatisfactory & 0 \\
Very unsatisfactory & 0 \\
Don't know & 0 \\
\hline Total & 6 \\
\hline
\end{tabular}

6) This question asks how attitudes of the Self-Help Information Service Staff have been toward the I \& $R$ worker.

TABLE XLV

ATTITUDES OF SIS STAFF TOWARD THE I \& R WORKER

\begin{tabular}{lc}
\hline \multicolumn{1}{c}{ Response } & Frequency \\
\hline Very satisfactory & 5 \\
Satistactory & 1 \\
Unsatisfactory & 0 \\
Very unsatisfactory & 0 \\
Don't know & 0 \\
\hline Total & 6 \\
\hline
\end{tabular}


7) This question asks to what extent the SIS goal of expanding the scope of $I \& R$ resources to include Self-Help groups in the Tri-County areas has been reached by the Self-Help Information Service.

TABLE XLVI

EXTENT SIS REACHED GOAL OF EXPANDING I \& R RESOURCES

\begin{tabular}{ll}
\hline \multicolumn{1}{c}{ Response } & Frequency \\
\hline & \\
Resources great 1y expanded & 2 \\
Resources somewhat expanded & 3 \\
Resources barely expanded & 1 \\
Resources not expanded & 0 \\
\hline Total & 6 \\
\hline
\end{tabular}

8) This question asks the worker to evaluate the effectiveness of SIS in reaching the overall goals of increasing I \& $R$ resources, linking self-help groups and prospective members and to provide accurate information about self-help groups to prospective members.

TABLE XIVII

EFFECTIVENESS OF SIS IN REACHING OVERALL GOALS

\begin{tabular}{lc}
\hline \multicolumn{1}{c}{ Response } & Frequency \\
\hline & \\
Very effective & 3 \\
Effective & 2 \\
Somewhat effective & 1 \\
Ineffective & 0 \\
Very ineffective & 0 \\
Don't know & 0 \\
\hline
\end{tabular}

9) This question asks for general feed-back about the Self-Help Information Service. 
TABLE XIVIII

IMPACT OF SIS ON I \& R SERVICE

Response

Frequency

Greatly Improved I \& $\mathrm{R}$ service 1

Improved $I \& R$ service 5

Had no effect on $I \& R$ service 0

Had somewhat negative impact on I \& $R$ service 0

Had great negative impact on I \& $R$ service 0

Total 6

This question also asks the open-ended question "What would make SIS more effective?" There were two responses with one caller suggesting more radio and television publicity and another responding "more time, experience and exposure", would improve the effectiveness of SIS. 
APPENDIX I

SELF-HELP GROUP RESPONSES TO THE SIS EVALUATION QUESTIONNAIRE

From the total inventory of 136 self-help groups, a random sample of 25 groups was selected. Twenty-four of the 25 group sample were contacted and completed the evaluation questionnaire. One group was defunct and unable to be contacted for the evaluation. Following are the results of the evaluation.

I. The first question asked whether or not the self-help group had contacted the Self-Help Information Service (SIS) to register their group with the service. Of the twenty-four total responses, six responded "yes" they did contact SIS to register a group, seventeen responded "no," and one "did not know."

TABLE XLIX

SIS CONTACTED BY SELF-HELP GROUP

\begin{tabular}{lcc}
\hline Response & Frequency & Proportion \\
\hline Yes & 6 & .25 \\
No & 17 & .71 \\
Don't Know & 1 & .04 \\
\hline Total & 24 & 1.00 \\
\hline
\end{tabular}

II. Question two asks for the self-help group contact person's opinion regarding whether having the group registered with SIS has been helpful to the group, e.g. brought the group new members or favorable notice, etc. Of twenty-four total responses, one responded "very 
helpful," nine responded "helpful," nine responded "unhelpful," none responded "a hindrance," and five responded "don't know."

TABLE L

\section{HELPFULNESS OF SIS REGISTRATION}

TO SELF-HELP GROUP

\begin{tabular}{lcc}
\hline \multicolumn{1}{c}{ Response } & Frequency & Proportion \\
\hline Very helpful & 1 & .04 \\
Helpful & 9 & .38 \\
Unhelpful & 9 & .38 \\
A hindrance & 0 & 0.00 \\
Don't know & 5 & .20 \\
\hline Total & 24 & 1.00 \\
\hline
\end{tabular}

III. Question three asked about group satisfaction with their contact with the Self-Help Information Service. Of the twenty-four total responses, nine responded "very satisfied," eight responded "satisfied," none responded "less than satisfied," none responded "very dissatified," and seven responded "don't know."

TABLE LI

SELF-HEIP GROUP SATISFACTION WITH SIS CONTACT

\begin{tabular}{lcc}
\hline \multicolumn{1}{c}{ Response } & Frequency & Proportion \\
\hline Very satisfied & 9 & .38 \\
Satisfied & 8 & .33 \\
Less than satisfied & 0 & 0.00 \\
Very dissatisfied & 0 & 0.00 \\
Don't know & 7 & .29 \\
\hline Total & 24 & 1.00 \\
\hline
\end{tabular}

IV. Question four probed for any comments or suggestions the group member might have about improving the SIS. There were 10 respondents who gave a total of 15 responses. Four respondents mentioned a need for 
more publicity of the SIS, three mentioned that more referrals to their group were needed, three respondents desired more information about SIS, two thought that follow-up of SIS referrals to self-help groups was needed, one mentioned a need for various support service (such as xeroxing, clerical resources, etc.) to be provided to self-help groups by SIS, one wanted more information about launching self-help groups, and one wanted more volunteer energy from SIS.

TABLE LII

SELF-HELP GROUP SUGGESTIONS FOR IMPROVING SIS

Response

\begin{tabular}{ll}
\hline \multicolumn{1}{c}{ Response } & Frequency \\
\hline SIS needs more publicity & 4 \\
More referrals to groups needed & 3 \\
More information needed about SIS & 3 \\
Follow-up of referrals needed & 2 \\
Support services for SHGs needed & 1 \\
Technical assistance & 1 \\
Staff assistance & 1 \\
\hline Total & 15 \\
\hline
\end{tabular}




\section{APPENDIX J}

\section{CALLER EVALUATION OF SIS}

IA. This question asked the interviewee if he/she talked to TriCounty I \& $R$ about a self-help group.

TABLE LIII

CONTACT WITH TRI-COUNTY I \& $R$

\begin{tabular}{lcc}
\hline Response & Frequency & Proportion \\
\hline Yes & 30 & .71 \\
No & 11 & .26 \\
No answer & 1 & .03 \\
\hline Total & 42 & 1.00 \\
\hline
\end{tabular}

IB. This question asked if the persons with whom contact was made at Tri-County $I \& R$ were friendly and helpful.

TABLE LIV

FRIENDLY AND HELPFUL $I$ \& $R$ STAFF

\begin{tabular}{lcc}
\hline Response & Frequency & Proportion \\
\hline Yes & 28 & .94 \\
No & 1 & .03 \\
No answer & 1 & .03 \\
\hline Tota1 & 30 & 1.00 \\
\hline
\end{tabular}


IIA. This question asked if the interviewee talked to Portland State University (RRI) about a self-help group.

TABLE LV

CONTACT WITH PSU

\begin{tabular}{lcc}
\hline Response & Frequency & Proportion \\
\hline Yes & 20 & .48 \\
No & 22 & .52 \\
\hline Total & 42 & 1.00 \\
\hline
\end{tabular}

IIB. This question asked if the personnel from PSU were friendly and helpful. All responses to this question were yes.

TABLE LVI

FRIENDLY AND HELPFUL PSU STAFF

\begin{tabular}{lcc}
\hline Response & Frequency & Proportion \\
\hline Yes & 20 & 1.00 \\
No & 0 & 0.00 \\
\hline Total & 20 & 1.00 \\
\hline
\end{tabular}

IIIA. This question asked if Tri-County $I \& R$ referred the interviewee to PSU or if PSU made a referral to Tri-County.

TABLE LVII

I \& R REFERRAL TO PSU OR PSU REFERRAL TO I \& $R$

\begin{tabular}{lcc}
\hline Response & Frequency & Proportion \\
\hline Yes & 6 & .35 \\
No & 11 & .65 \\
\hline Total & 17 & 1.00 \\
\hline
\end{tabular}


IIIB This question asked those who were referred by one to the other if Tri-County I \& R and PSU gave consistent information.

\section{TABLE LVIII}

CONSISTENT INFORMATION GIVEN

BY I \& R AND PSU

\begin{tabular}{lcc}
\hline Response & Frequency & Proportion \\
\hline Yes & 4 & .67 \\
No & 2 & .33 \\
\hline Total & 6 & 1.00 \\
\hline
\end{tabular}

IV. This question asked if the interviewee had any difficulty finding out about or contacting sis. Most respondents indicated no trouble.

TABLE LVIX

DIFFICULTY CONTACTING SIS

\begin{tabular}{lcc}
\hline Response & Frequency & Proportion \\
\hline Yes & 7 & .17 \\
No & 32 & .76 \\
Don't know & 3 & .07 \\
\hline Total & 42 & 1.00 \\
\hline
\end{tabular}

This question also asked what difficulties were encountered by those seven respondents who answered "yes" above. 
TABLE LX

DIFFICULTIES ENCOUNTERED IN CONTACTING SIS

\section{Response}

Not enough publicity of SIS

Too many months of contact to get a group

$I \& R$ lacked specific needed information on self-help groups

SIS person out of the office when respondent tried to contact

Call-backs took too long
Frequency

3

1

1

1

Proportion

Total

7

.4300

.1425

.1425

.1425

.1425

1.0000

V. This asked of the respondents to describe their feelings about calling SIS. Most feelings were neutral to positive.

TABLE LXI

RESPONDENTS' FEELINGS ABOUT

CALLING SIS

\begin{tabular}{lcc}
\hline Response & Frequency & Proportion \\
\hline Very negative & 0 & 0.00 \\
Negative & 1 & .02 \\
Neutral & 9 & .22 \\
Positive & 10 & .24 \\
Very positive & 19 & .45 \\
No answer & 3 & .07 \\
\hline Total & 42 & 1.00 \\
\hline
\end{tabular}

VIA. This question asked if the interviewee called about membership for her/himself in a self-help group. Most answered "yes."

TABLE LXII

CALLERS ASKING FOR MEMBERSHIP

\begin{tabular}{lcc}
\hline Response & Frequency & Proportion \\
\hline Yes & 33 & .79 \\
No & 9 & .21 \\
\hline Tetal & 42 & 1.00 \\
\hline
\end{tabular}


VIB. This question asked what the person called for if not for information about membership in a self-help group.

Table LXIII

CALLERS ASKING FOR INFORMATION OTHER THAN MEMBERSHIP

\begin{tabular}{lcc}
\hline Response & Frequency & Proportion \\
\hline $\begin{array}{l}\text { People were professionals calling for a } \\
\text { client }\end{array}$ & 3 & .34 \\
$\begin{array}{l}\text { People were simply calling for someone } \\
\text { else }\end{array}$ & 2 & .22 \\
$\begin{array}{l}\text { People just wanted further information } \\
\text { Person was interested in a directory }\end{array}$ & 2 & .22 \\
Person wanted information about how SIS & 1 & .11 \\
$\quad$ works & 1 & .11 \\
\hline Total & 9 & 1.00 \\
\hline
\end{tabular}

VIC. This question asked the interviewees how satisfied they are with the responses to their requests which they received from SIS. Most respondents indicated satisfaction.

TABLE LXIV

CALLER SATISFACTION WITH RESPONSES FROM SIS

\begin{tabular}{lcc}
\hline \multicolumn{1}{c}{ Response } & Frequency & Proportion \\
\hline Very satisfied & 12 & .29 \\
Satisfied & 16 & .38 \\
Dissatisfied & 5 & .12 \\
Very dissatisfied & 0 & 0.00 \\
Not applicable & 2 & .05 \\
No Answer & 7 & .16 \\
\hline Total & 42 & 1.00 \\
\hline
\end{tabular}


VII. This question asked if the person was referred to a group.

TABLE LXV

CALLERS REFERRED TO A GROUP

\begin{tabular}{lcc}
\hline Response & Frequency & Proportion \\
\hline & 11 & \\
At once & 13 & .26 \\
Later & 13 & .31 \\
Not referred & 18 & .43 \\
\hline Total & 42 & 1.00 \\
\hline
\end{tabular}

VIIIA. This question asked which group the respondent was referred to.

TABLE LXVI

GROUPS REFERRED

\begin{tabular}{lcc}
\hline \multicolumn{1}{c}{ Response } & Frequency & Proportion \\
\hline Women's Support Group & 5 & \\
New Hope Positive Singles & 2 & .21 \\
Step-parents & 6 & .08 \\
Diabetic Support & 2 & .25 \\
Other & 9 & .08 \\
\hline Total & .38 \\
\hline
\end{tabular}

VIIIB. This question asked if the interviewee had any difficulty contacting a group representative.

TABLE LXVII

DIFFICULTIES IN CONTACTING

A GROUP REPRESENTATIVE

\begin{tabular}{lcc}
\hline Response & Frequency & Proportion \\
\hline & 2 & \\
Yes & 16 & .08 \\
No & 1 & .66 \\
Don't know & 5 & .05 \\
Did not try & .21 \\
\hline Total & 24 & 1.00 \\
\hline
\end{tabular}


VIIIC. This question asked if the interviewee has attended any group meetings.

\section{TABLE LXVIII}

ATTENDANCE AT GROUP MEETINGS

\begin{tabular}{lcc}
\hline Response & Frequency & Proportion \\
\hline Yes & 9 & .38 \\
No & 15 & .62 \\
\hline Total & 24 & 1.00 \\
\hline
\end{tabular}

This question also asked of the respondents answering "yes" how many meetings they had attended.

TABLE LXIX

NUMBER OF MEETINGS ATTENDED

\begin{tabular}{lcc}
\hline Response & Frequency & Proportion \\
\hline One meeting & 7 & .78 \\
Two & 1 & .11 \\
Three & 1 & .11 \\
Over three & 0 & 0.00 \\
\hline Total & 9 & 1.00 \\
\hline
\end{tabular}

This question asked of the respondents answering "no" what their reasons were for not attending. 
TABLE LXX

REASONS FOR NON-ATTENDANCE

\section{Response}

Lack of transportation

It was too far to the self-help group

An emergency came up

The group hadn't started yet

Pregnancy interfers with attendance now

Too busy and hadn't had time to call

The referral came too late for her client

It was "not the group he wanted"

Total

VIIID. This question asked if the referral which was made was

TABLE LXXI

REFERRALS APPROPRIATE

\begin{tabular}{lcc}
\hline Response & Frequency & Proportion \\
\hline & 8 & .89 \\
Yes & 1 & .11 \\
No & 0 & 0.00 \\
Don't know & 0 & 1.00 \\
\hline Total & 9 &
\end{tabular}

VIIIE. This question asked if the concerns and interests of the group members were similar to the interviewee's

TABLE LXXII

GROUP MEMBERS' CONCERNS SIMILAR TO RESPONDENTS' CONCERNS

\begin{tabular}{lcc}
\hline Response & Frequency & Proportion \\
\hline & & \\
Yes & 4 & .44 \\
Somewhat & 4 & .44 \\
No & 4 & .12 \\
Don't know & 0 & 0.00 \\
\hline Total & 9 & 1.00 \\
\hline
\end{tabular}


VIIIF. This question asked if the interviewee is still attending group meetings.

TABLE LXXIII

CONTINUING ATTENDANCE AT

GROUP MEETINGS

\begin{tabular}{lcc}
\hline Response & Frequency & Proportion \\
\hline Yes & 4 & .44 \\
No & 5 & .56 \\
\hline Total & 9 & 1.00 \\
\hline
\end{tabular}

This question also asked of those who were not still attending meetings why not.

TABLE LXXIV

REASONS FOR TERMINATING ATTENDANCE AT GROUP MEETINGS

Response Frequency

Proportion

The group was not what he wanted in a group

Too busy to attend and had time conflict

Professionally checking out the meeting

The age range of the group was "wrong"

The group was depressing

Total Prequenc 
TABLE LXXV

CONCERNS/NEEDS MET BY GROUP

\begin{tabular}{lcc}
\hline Response & Frequency & Proportion \\
\hline Yes & 3 & .75 \\
No & 0 & 0.00 \\
Somewhat & 1 & .25 \\
Don't know & 0 & 0.00 \\
\hline Total & 4 & 1.00 \\
\hline
\end{tabular}

This question also asked of those who were still attending meetings if they plan to continue attending.

TABLE LXXVI

PLANS TO CONTINUE ATTENDING GROUP MEETINGS

\begin{tabular}{lcc}
\hline Response & Frequency & Proportion \\
\hline & 3 & .75 \\
Yes & 1 & .25 \\
No & 0 & 0.00 \\
Don't know & 0 & 1.00 \\
\hline Total & 4 &
\end{tabular}

of those who will not continue, why is asked: One person said $\mathrm{s} / \mathrm{he}$ was moving away.

IX. This question asked the interviewees who had attended group meetings if the group had made a difference in the way they felt about their concerns. 
TABLE LXXVII

IMPACT OF GROUP ON CALLERS' FEELINGS

ABOUT THEIR CONCERNS

\begin{tabular}{lcc}
\hline \multicolumn{1}{c}{ Response } & Frequency & Proportion \\
\hline Much better & 2 & .22 \\
Better & 2 & .22 \\
Just the same & 4 & .44 \\
Worse & 0 & 0.00 \\
Much worse & 0 & 0.00 \\
No answer & 1 & .12 \\
\hline Total & 9 & 1.00 \\
\hline
\end{tabular}

$\mathrm{XA}$. This question asked the interviewees if they were asked to be on a waiting list. Over half said yes.

TABLE LXXVIII

$$
\text { REQUESTED BY STAFF TO BE ON }
$$

A WAITING LIST

\begin{tabular}{lcc}
\hline \multicolumn{1}{c}{ Response } & Frequency & Proportion \\
\hline Yes & 22 & \\
No & 17 & .52 \\
Not applicable & 2 & .40 \\
No answer & 1 & .05 \\
\hline Total & .03 \\
\hline
\end{tabular}

$X B$. This question asked if the interviewees who were asked to be on a waiting list agreed to be on a waiting list.

TABLE LXXIX

AGREED TO BE ON A WAITING LIST

\begin{tabular}{lcc}
\hline Response & Frequency & Proportion \\
\hline Yes & 21 & .95 \\
No & 1 & .05 \\
\hline Total & 22 & 1.00 \\
\hline
\end{tabular}


$\mathrm{XC}$. This question asked the interviewees who agreed to be on a waiting list how satisfied they were with being put on a waiting list if there was no group available to refer them to. Most indicated satisfaction.

TABLE LXXX

SATISFACTION WITH PLACEMENT ON WAITING

LIST WHEN NO GROUP AVAILABLE

\begin{tabular}{lcc}
\hline \multicolumn{1}{c}{ Response } & Frequency & Proportion \\
\hline Very satisfied & 3 & .14 \\
Satisfied & 14 & .66 \\
Less than satisfied & 2 & .10 \\
Very dissatisfied & 1 & .05 \\
No answer & 1 & .05 \\
\hline Total & 21 & 1.00 \\
\hline
\end{tabular}

XIA. This question asked the interviewees if they were told the SIS staff would re-contact them. The great majority said "yes."

TABLE LXXXI

TOLD SIS STAFF WOULD RE-CONTACT

\begin{tabular}{lcc}
\hline \multicolumn{1}{c}{ Response } & Frequency & Proportion \\
\hline Yes & 32 & .76 \\
No & 7 & .17 \\
Not applicable & 3 & .07 \\
\hline Total & 42 & 1.00 \\
\hline
\end{tabular}


XIB. This question asked of those who said "yes" if the SIS staff actually did re-contact them.

\section{TABLE LXXXII}

SIS STAFF DID RE-CONTACT

\begin{tabular}{lcc}
\hline Response & Frequency & Proportion \\
\hline Yes & 26 & .81 \\
No & 6 & .19 \\
\hline Total & 32 & 1.00 \\
\hline
\end{tabular}

XIC. This question asked of those who were re-contacted if the SIS person was friendly and helpful.

\section{TABLE LXXXIII}

SIS STAFF FRIENDLY AND HELPFUL

\begin{tabular}{lcc}
\hline Response & Frequency & Proportion \\
\hline Yes & 25 & .96 \\
No & 1 & .04 \\
\hline Total & 26 & 1.00 \\
\hline
\end{tabular}

XIIA. This question asked the interviewees if they agreed to help form a group.

TABLE LXXXIV

AGREED TO HELP FORM A GROUP

\begin{tabular}{lcc}
\hline \multicolumn{1}{c}{ Response } & Frequency & Proportion \\
\hline & & \\
Yes & 18 & .43 \\
No & 19 & .46 \\
Not applicable & 5 & .11 \\
\hline Total & 42 & 1.00 \\
\hline
\end{tabular}


XIIB. This question asked the interviewees who agreed to help form a group if they have had the opportunity to do so.

TABLE LXXXV

HAVE HAD OPPORTUNITY TO HELP FORM A GROUP

\begin{tabular}{lcc}
\hline Response & Frequency & Proportion \\
\hline Yes & 2 & .11 \\
No & 16 & .89 \\
\hline Total & 18 & 1.00 \\
\hline
\end{tabular}

XIIC. This question asked of those who have had the opportunity to help form a group if the procedures for forming a group were helpful or not.

TABLE LXXXVI

HELPFULNESS OF PROCEDURES

FOR FORMING A GROUP

\begin{tabular}{lcc}
\hline Response & Frequency & Proportion \\
\hline & 0 & \\
Very helpful & 0 & 0.00 \\
Helpful & 2 & 1.00 \\
Unhelpful & 0 & 0.00 \\
A hindrance & 0 & 0.00 \\
\hline Total & 2 & 1.00 \\
\hline
\end{tabular}


XIIIA. This question asked the interviewees if SIS provided them with accurate information.

TABLE LXXXVII

SIS PROVIDED ACCURATE INFORMATION

\begin{tabular}{lcc}
\hline Response & Frequency & Proportion \\
\hline Yes & 33 & .79 \\
No & 2 & .05 \\
Don't know & 7 & .16 \\
\hline Total & 42 & 1.00 \\
\hline
\end{tabular}

of the two who said "no," one person said, "The referral I was given is not now sponsoring a group," and one person said, "Longer than two weeks for the call-back."

XIIIB. This question asked if the interviewees would refer a friend or relative to SIS.

TABLE LXXXVIII

WILLING TO REFER A FRIEND

OR RELATIVE TO SIS

\begin{tabular}{lcc}
\hline Response & Frequency & Proportion \\
\hline & & \\
Yes & 36 & .86 \\
No & 1 & .02 \\
Don't know & 5 & .12 \\
\hline Total & 42 & 1.00 \\
\hline
\end{tabular}


XIVA. This question asked the interviewees how satisfied they are with the service they received from SIS, all things considered.

TABLE LXXXIX

OVERALL SATISFACTION WITH SIS

\begin{tabular}{lcc}
\hline \multicolumn{1}{c}{ Response } & Frequency & Proportion \\
\hline Very satisfied & 15 & \\
Satisfied & 20 & .36 \\
Dissatisfied & 3 & .48 \\
Very dissatisfied & 0 & .07 \\
Don't know & 4 & 0.00 \\
\hline Total & 42 & .09 \\
\hline
\end{tabular}

XIVB. This question asked for specific reasons for satisfaction/ dissatisfaction.

TABLE XC

REASONS FOR SATISFACTION/DISSATISFACTION

\section{Response}

No response to her call in December

No information received about a group

Felt she was always being referred to someone else

"There is no group yet"

Inappropriate referral

Too long to get a group going

Follow-up

Much unrealized potential

Friendly service

Got needed information

SIS supplied information in a meaningful, helpful way

Experienced SIS staff who are concerned about the individual

Positive feeling that "something could be done

No comment

Total
Frequency

Proportion

$1 \quad .02$

$1 \quad .02$

$1 \quad .02$

$2 \quad .04$

$1 \quad .02$

$1 \quad .02$

$1 \quad .02$

$1 \quad .02$

$1 \quad .02$

$5 \quad .12$

$12 . \quad .29$

$5 \quad .12$

20

$42 \square 1.00$


XV. This question asked the interviewees for any further comments, criticisms or suggestions about SIS.

TABLE XCI

FURTHER COMMENTS ABOUT SIS

Response

More publicity needed

Disappointed--waiting

Praise for SIS

Transportation services needed

Appreciated SIS staff re-contacting

SIS should screen for desperate people

who need help immediately

Inappropriate referral

Request for guidelines in regard to

forming a group

The poster is vague

Who/what is SIS

Screen for age, interests, needs before referring

Be concerned for handicapped in regard to referrals

Contact didn't have immediate information and took too long

Self-help groups a good idea

Need a master list available for those who request one

Wants to be re-contacted as appropriate group surfaces

No comment
Erequency

Proportion

$6 \quad .14$

$4 \quad .10$

$5 \quad .12$

$2 \quad .04$

$1 \quad .02$

$2 \quad .04$

$1 \quad .02$

$1 \quad .02$

$1 \quad .02$

$1 \quad .02$

$1 \quad .02$

$1 \quad .02$

$1 \quad .02$

$1 \quad .02$

$2 \quad .04$

$1 \quad .02$

$13 \quad .32$

Total

42

1.00 
SELF-HELP PROJECT STAFF QUESTIONNAIRE

Date of Interview

Name of Interviewer
Name of Interviewee

Position/Title

of Interviewee

The mission of the Self-Help Information Service (SIS) is to expand the quality and scope of human services available to meet communty members' needs via the development and maintenance of an Information and Refer ral Service.

More specifically, the goals of SIS are to search out and inventory all self-help Eroups in the Tri-County area and to link potential members in the community with specific needs to available and appropriate groups to meet those needs.

Please evaluate your involvement in the following tasks associated with developing the Self-Help Information and Referral Service:

I. Approxinately how many hours per week have you spent in the last 4 months?

IA. 1) Inventory. Searching for and collecting information on self-help groups, i.e. filling out the white sheets?

$$
\text { (If } 0 \text {, go to \#A4) }
$$

2) This amount of time was:

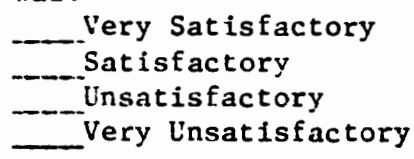

3) If Unsatisfactory, why:

4) For capturing the needed facts are the inventory forms:

Very Useful

Useful

Tot Useful

Don't know
IB. 1) Potential Inventory. Recontacting potential members to explain the SIS, i.e. working on yellow sheets?

(if 0 , go to (4)

2) This amount of time was:

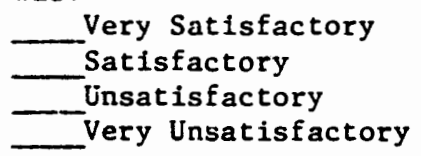

3) If unsatisfactory, why:

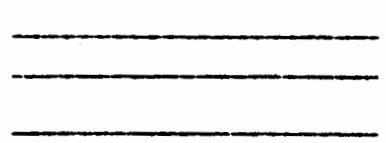

4) For capturing the needed facts, is the potential member questionnaire:

Very Useful

Use ful

Not Usefu1

Don't know
IC. 1) Information Campaign Working on the information campaign, i.e. delivering posters, sending press releases? (If 0 , go to \#CA)

This amount of time was: Very Satisfactory Satisfactory Unsatisfactory Very Insatisfactory

3) If unsatisfactory, why:

4) For conveying the needed facts to groups and potential nembers, the poster is:

Very Useful Useful Not Useful Don't Know 
Inventory

5) A. Are inventory procedures:

Cumbersone Adequate \& Comprehensive Sketchy \& Inadequate Don't Know

6) A. Were you given clear directions for the Inventory?

Yes

No

Somewhat Not Applicable

7) A: Are you comfortable contacting groups to inventory?

\begin{tabular}{l} 
Yes \\
No \\
\hline Somewhat \\
\hline If not, why?
\end{tabular}

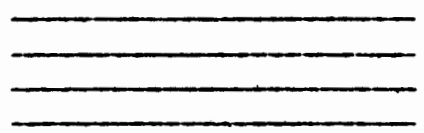

Potential Members

5) B. Are potential member procedures:

Cumber some

Adequate \&

Comprehensive

Sketchy \&

Inadequate

Don't know

6) B. Were you given clear directions for the questionnaire?

Yes
No
Somewhat
Not Applicable

7) A. Are you comfortable contacting potential members?

\begin{tabular}{l} 
Yes \\
No \\
\hline Somewhat
\end{tabular}

If not, why?

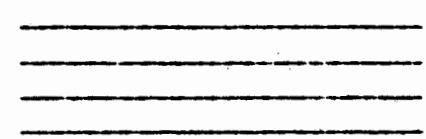

Information Campaign

5) C. Are information campaign procedures:

Cumbersome

Adequate \&

Comprehensive

Sketchy \&

Inadequate

Don't know

6) C. Were you given clear directions for the information campaign?

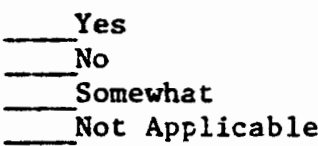

7) C. Are you comfortable disseminating information about SIS \& SHP?
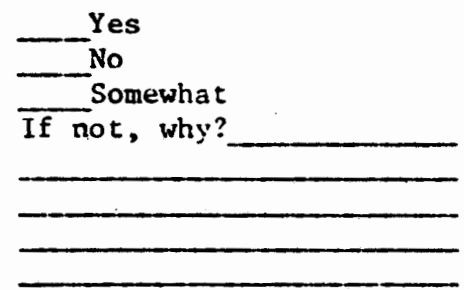

II.A. Are you satisfied with the way Self-help Information Service (SIS) handles the referrals in general?

Very Satisfied

Satisfied

Dissatisfied

Very Dissatisfied

Dont Know

B. If you are not satisfied, how might the handling of referrals be improved? 
III. SIS Project Staff used the Information and Referral resource list and files as a starting point in their search for self-help groups. Information and Referral also provides a 40-hour per week phone service to collect and disseminate information for SIS. In return, SIS staff and students provide 16-24 hours of "volunteer" time to help on the phones and keep Information and Referral current of new self-help group resources.

A. Approximately how many hours per week do you spend at I \& R?

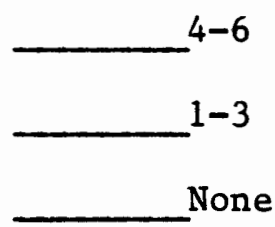

B. Is this arrangement:

Very Satisfactory Satisfactory

Less than Satisfactory

Very Unsatisfactory

Not Applicable

C. Was your training for work at Information \& Referral:

Very Satisfactory

Satisfactory

Unsatisfactory

Very Unsatisfactory

Not Applicable

IV.A. Attitudes of Self-Help Program staff toward you as a co-worker have been:

Very Satisfactory

Satisfactory

Less than Satisfactory

Very Unsatisfactory 
B. Attitudes of Information \& Referral staff toward you as a co-worker have been :

$\begin{array}{ll}\text { Very Satisfactory } & \text { Very Unsatisfactory } \\ \text { Satisfactory } & \text { Don't Know } \\ \text { Unsatisfactory } & \text { Not Applicable }\end{array}$

V. A. Overall, how satisfied are you with the Self-Help Information Service?

Very Satisfied

Satisfied

Dissatisfied

Very Dissatisfied

Don't know

B. What would make you more satisfied with the service?

VI. A. TO THE PRINCIPAL INVESTIGATOR

1) Is the Self-Help Information Service fulfilling your expectations as you conceived of SIS in the grant?

More than fulfilling expectations

Fulfilling expectations

Not fulfilling expectations

Don't know

2) If SIS is not fulfilling your expectations (as per the grant), what should be done differently?

B. TO THE PROJECT DIRECTOR:

In terms of the over-all goals of the self-help project, and more specifically around the coordination of staff time and energy in meeting those goals:

1) How satisfied are you with the proportion of staff time and energy invested in SIS?

Very Satisfied Not Satisfied

Somewhat satisfied Don't know 
2) In terms of effectiveness, how could staff time and energy be improved?

3) How useful and instrumental is SIS in furthering the attainment of the overall research goals?

Very Useful Useful Don't Know WHY?

VI. C. TO THE STUDENTS

1) How useful has your involvement with the Self-Help Information Service been toward expanding your knowledge base of research and self-help groups in general?

Very Useful

Somewhat Useful
Not Useful

Don't know

2) If not useful, what would have made your experience better?

VI. D. TO THE STAFF

How useful has your involvement with the Self-Help Information Service been in providing work experience useful for professional advancement?

Very Useful

Somewhat Useful

Not Useful

Don't know 
APPENDIX L

TRI-COUNTY INFORMATION AND REFERRAL STAFF QUESTIONNAIRE

Date

Name of Interviewer

Name of Interviewee

Title of Interviewee

1. The major task you have been asked to perform by the SIS staff is filling out the Potential Member Interview forms (yellow sheets).

A. Please describe procedures for using the Potential Member forms:

If group available:

1. Make referral

2. Explain about evaluation of SIS

3. Fill out yellow sheet (at least name, concern \& number)

4. Note what referral was made on yellow sheet

5. Place in Self-Help Project box for pick-up by SIS staff

If group not available:

1. Explain that a SIS team member will re-contact within one week

2. Fill out yellow sheet (at least name, concern, number and if person is willing to be on a waiting list)

3. Place in SIS box for pick-up by SIS staff

B. Were you given clear directions and/or training to work with the forms?

Yes _ـ No __ Somewhat _ Not applicable

C. Are you confortable responding to Potential Member calls?

Yes No No Somewhat __ Not applicable

D. Are the procedures for handling Potential Member calls:

Cumbersome

Comprehensive and adequate

Sketchy and inadequate 
E. How might the Potential Member procedures be improved?

2. The second major task you have been asked to perform by SIS is partially filling out the Group Inventory form (the white sheet).

A. Please describe procedures for using the Group Inventory forms:

1. Explain the purpose of SIS

a. Linking function

b. Explain SIS staff will re-contact within week

2. Get name of the group, two contact person's names and phone numbers and the purpose of the group. Fill out the appropriate spaces on the white sheet.

3. Place in SIS box for pick-up by SIS staff

B. Were you given clear directions and/or training to work with the forms?

Yes

No

Somewhat

Not Applicable

C. Are you comfortable responding to calls from Self-Help Groups?

Yes No

Somewhat

Not Applicable

If No or Somewhat, what are you uncomfortable with?

D. Are procedures for handling Group Inventory contacts:

Cumbersome

Comprehensive and adequate

Sketchy and inadequate

E. How might the inventory procedures be improved? 
3. A. Potential members call $I \& R$ for information and referral for various concerns. If a group is available, is the referral made promptly?

All the time
Most of the time
Some of the time

All the time
Most of the time

B. If a group is not available, the contact information (yellow sheet) is sent to the SIS staff. Are you satisfied with the way SIS then handles the referrals?

$\begin{array}{ll}\text { Very satisfied } & \text { Less than satisfied } \\ \text { Satisfied } & \text { Don't know }\end{array}$

If you are not completely satisfied, how might the handling of referrals be improved?

4. A. Does your agency have any written material incorporating SIS procedures into the general Information and Referral procedures? Yes No Don't know

B. Do you have a picture of the total system of the service (i.e. where the yellow and white forms go and when and how the forms are used)?

Yes __ No Somewhat Not applicable

C. If no, would orientation designed to give a view of the SIS system be helpful to you?

Yes ___ No Somewhat ___ Not applicable

D. In day-to-day on-line functioning, have SIS procedures been: Disruptive Smooth Facilitative 
5. Project staff used the $I \& R$ resource list and files as a starting point in their search for self-help groups. I \& $R$ also provides a 40-hour per week phone service to collect and disseminate information for SIS. In return, Self-Help project staff and students provide 16-24 hours of "volunteer" time to help on the $I \& R$ phones and keep $I \& R$ current of new Sëlf-Help group resources.

A. Is this arrangement:

Very satisfactory
Satisfactory
Unsatisfactory
Very unsatisfactory Don't know

6. A. Attitudes of the SIS staff to you have been:

Very satisfactory
Satisfactory
Unsatisfactory

Very unsatisfactory Don't know

7. A. A major goal of the Self-Help Information Service is to expand the scope of $I \& R$ resources to include Self-Help Groups in the Tri-County Area. To what extent has this goal been reached by SIS?

Resources greatly expanded

Resources somewhat expanded

Resources barely expanded

Resources not expanded

8. The major goals of SIS are increasing $I \& R$ resources, to help link self-help groups and prospective members, and to provide accurate information about self-help groups to prospective members. Overall, how effective do you think SIS is in reaching these goals?

$\begin{array}{ll}\text { Very effective } & \text { Very ineffective } \\ \text { Effective } & \text { Don't know } \\ \text { Ineffective } & \longrightarrow\end{array}$

What would make SIS more effective? 
9. In general, the Self-Help Information Service has:

Greatly improved I \& $R$ service

Improved $I \& R$ service

Had no effect on $I \& R$ service

Had somewhat negative impact on $I \& R$ service

Had great negative impact on I \& $R$ service 


\section{APP ENDIX M}

GROUP QUESTIONNAIRE

Date of Interview

Name of Interviewer
Name of Interviewee

Title of Interviewee

I. Did you call to register a self-help group? YES

NO

II. If YES, has registering your group been helpful to you, e.g. brought new members or favorable notice, etc?

Very Helpful

Helpful
Unhelpful

A Hindrance

III. How satisfied were you with your contact with the Self-Help Information Service (SIS)?

Very Satisfied
Satisfied
Less than satisfied

IV. Do you have any comments or suggestions for improving SIS? 
Date

Name of Interviewee

Name of Interviewer

Title of Interviewee

We understand that you have recently called about a Self-Help group. We would like for you to help us evaluate the Self-Help Information Service. Would you take about five minutes to answer a few questions about how your call was recelved?

First, we would like to understand the contact that you have had with the Self-Help Group Information Service.

1. a. Did you talk to Tri-County I \& R about a Self-Help Group (2225555)?

Yes No

b. Were they friendly and helpful?

Yes No

2. a. Did you talk to Portland State University about a Self-Help Group (229-4040)? Yes No

b. Were they friendly and helpful?

Yes No

3. a. Did either number refer you to the other?

Yes No

b. Did the two places give you consistent information? Yes No Not applicable 
4. Did you have any difficulty finding out about or contacting the Self-Help Group Information Service (SIS)? Yes No Don't know

If Yes. what was/were the difficulty/difficulties you encountered?

5. How would you describe your feelings about calling the Self-Help Group Information Service?

Very negative
Negative
Neutral
Positive Very Positive Neutral

6. a. Did you call to ask about membership for yourself in a SelfHelp Group? Yes No

b. If no, what request did you make? (If Yes, go to $\#^{7}$ )

c. How satisfied were you with the response to your request which you received?

\begin{tabular}{l} 
Very satisfied \\
Satisfied \\
\hline Dissatisfied
\end{tabular}

Very Dissatisfied
Not applicable

7. Were you referred to a group: _

8. a. What group were you referred to?

b. Did you have any difficulty contacting a group representative? Did not try __ Yes No No Don't know 
c. Have you attended any group meetings? Yes Nò

If Yes, how many?

If none. what were your reasons for not attending--then go to \#10:

d. Was that an appropriate referral?
Yes
No
Don't know

e. Were the concerns and interests of the members similar to yours? Yes No No Somewhat Don't know

f. Are you still attending meetings? Yes No Not applicable

If not, why not?

1) If yes, are your concerns or needs being met by the group? Yes ___ No Somewhat Don't know

2) Do you plan to continue attending meetings?
Yes
No
Don't know

If not, why not?

9. Did the group make a difference in the way you feel about your concern? Do you feel:

Much better

Worse

Better

Much worse

Just the same

Not applicable

10. a. Were you asked to be on a waiting list for any groups?

Yes No

Not applicable 
b. Did you agree to be on a waiting list?

Yes No No Not applicable

c. If there was no existing group to refer you to, how satisfied were you with being put on a waiting list?

$\begin{array}{ll}\text { Very satisfied } & \text { Very dissatisfied } \\ \text { Satisfied } & \text { Don't know } \\ \text { Less than satisfied } & \text { Not applicable }\end{array}$

11. a. Were you told that the Self-Help staff would re-contact you?

Yes ㄴ№ No Not applicable

b. Did they?

Yes No No Not applicable

c. If Yes, were they friendly and helpful?

Yes No No Not applicable

12. a. Did you agree to help form a group?

Yes No Not No applicable

(If yes, specify which group)

b. Have you had the opportunity to help form a group?

Yes No Not applicable

(If yes, specify which group)

c. If yes, were the procedures for forming a group:

Very helpful Unhelpful Helpful A hindrance

d. How could these procedures be improved? 
13. a. Has the Self-Help Information Service provided you with accurate information?

Yes

No

Don't know

If no, what was inaccurate?

b. Would you refer a friend or relative to the Self-Help Information Service?

Yes N_ No Don't know

14. a. All things considered, how satisfied were you with the service you received from SIS?

$\begin{array}{ll}\text { Very Satisfied } & \text { Very Dissatisfied } \\ \text { Satisfied } & \text { Don't know } \\ \text { Dissatisfied } & \end{array}$

b. What were your reasons for being satisfied/dissatisfied?

15. Do you have any further comments, criticisms or suggestions about the self-Help Information Service? 


\section{BIBLIOGRAPHY}

APA Publication Manual Task Force, "Guidelines for Nonsexist Language in APA Journals," Publication Manual, Vo1. 2, Washington, D.C.: American Psychological Association, 1977.

Ascheim, B., Horman, E., Queisser, T., and Silverman, P., Development of Special Mental Health Technical Assistance Materials for SelfHelp Groups in Particular Populations, Cambridge: American Institutes for Research, 1978.

Attkisson, C., Hargreaves, W., Horowitz, M. and Sorensen, J., Evaluation of Human Service Programs, Academic Press: New York, 1978.

Babbie, E., Survey Research Methods, Belmont, CA: Wadsworth, 1973.

Bakker, B., and Karel, M., "Self-Help Groups and Mutual Aid in the Netherlands: A Survey Research," Unpublished Manuscript, University of Amsterdam, 1980a.

Bakker, B., and Karle, M., "Self-Help in the Netherlands: A Descritpion," Unpublished Manuscript, University of Ansterdam, 1980b.

Berlin, D., "Evaluation of a Mental Health Information and Referral Service," Community Mental Health Journal, 6 (2), 1970.

Bloom, B., Community Mental Health: A General Introduction, Monterey, Ca.: Brooks/Cole, 1975.

Bowers, G., and Bowers, M., "Cultivating Client Information Systems,"

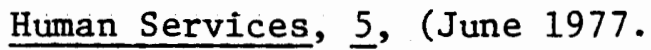

Brenner, M., Mental Illness and the Economy, Cambridge, Ma.: Harvard University Press, 1973. 
Bumbalo, H. and Young, D., "The Self-Help Phenomenon," American Journal of Nursing, 73 (9), September 1973.

Campbel1, D., and Stanley, J,, Experimental and Quasi-Experimental Designs for Research, Chicago: Rand McNally \& Co., 1963,

Caplan, G., Support Systems and Community Mental Health, New York: Behaviora1 Publications, 1977.

Caplan, G., Support Systems in Mental Health: Lectures on Concept Development, New York: Human Services Press, 1974.

Chafetz, M. and Demone, H., Jr., Alcoholism and Society, New York: Oxford University Press, 1962.

Chamberlin, J., On Our Own, New York: McGraw-Hil1, 1979.

Collins, A., and Pancoast, D., "Natural Helping Networks," Washington: National Association of Social Workers, 1976.

Comptroller General of the United States, Information and Referral for

People Needing Human Services--A Complex System That Should be Improved, Washington, D.C.: Report to Congress, 1978.

Cutler, D., "The Chronically Mentally I1l," Community Mental Health, Silverman, W., (ed.), New York: Praeger, 1981.

Dean, S., "Self-Help Groups' Psychotherapy: Mental Patients Rediscover Will Power," International Journal of Psychiatry, 17, 1971, pp.72-78.

Dean, S., "The Role of Self-Conducted Group Therapy in Psychorehabilitation: A Look at Recovery, Inc." American Journal of Psychiatry, 127 (7), 1971, pp.110-113.

Dehner, J., "The Network Concept in Information and Referral," Information and Referral, 1 (3), 1979. 
Delbecq, A., Van de Ven, A., and Gustafson, D., Group Techniques for Program Planning, Chicago: Scott, Foresman \& Co., 1975.

Dumont, M., "Self-Help Treatment Programs: An Overview," American Journal of Psychiatry, 131 (6), June 1974.

Gartner, A., and Riessman, F,, Self-Help in the Human Services, San Francisco: Jossey Bass Publishers, 1977.

Garwick, G. and Larsen, N., Introductory Workshop on Client Satisfaction Surveys, Minneapolis: Program Evaluation Resource Center, 1976. Goldman, H., et al, "Defining and Counting the Chronically Mentally Ill," Hospital and Community Psychiatry, 32 (1), 1981, pp. 21-26.

Goldstein, H., Research Standards and Methods for Social Workers, Chicago: Whitehall, 1969.

Goode, W., and Hatt, P., Methods in Social Research, New York: McGraw-Hill, 1952 .

Hatfield, A., "The Family as Partner in the Treatment of Mental Illness," Hospital and Community Psychiatry, 30 (5), 1979, pp.338-340.

Hobbs, N., "Mental Healths' Third Revolution," American Journal of Orthopsychiatry, 34 (5), 1964.

Hurvitz, N., "Peer Self-Help Psychotherapy Groups and Their Implications for Psychotherapy," Psychotherapy: Theory, Research, and Practice, I (1), 1970, pp.41-49.

Hurvitz, N., "Peer Self-Help Psychotherapy Groups: Psychotherapy Without Psychotherapists," in Roman and Trice, (eds.), The Sociology of Psychotherapy, New York: Jason Aronson, 1974. Hurvitz, N., "The Origins of the Peer Self-Help Psychotherapy Group Movement," Journal of Applied Behavioral Science, Vol, 12, 1976, pp. 283-294. 
Isenberg, D., Directory of Self-Help Groups for Serious and Chronic

IIlnesses and Bereavement, Chicago: Project Hope of Northeastern Illinois University, 1980.

Katz, A., and Bender, E., "Self-Help Groups in Western Society: History and Prospects," The Journal of Applied Behavioral Science, 12 1976, pp. 265-282.

Kropotkin, P., Mutual Aid: A Factor of Evolution, New York: New York University Press, 1972.

Lamb, H., Community Survival for Long-Term Patients, San Francisco: Jossey-Bass, 1976.

Lamb, H., and 0liphant, E., "Parents of Schizophrenics: Advocates for the Mentally Ill," in Stein, L. (ed.) Community Support Systems for the Long Term Patient: New Directions for Mental Health Services, Vol. 2, San Francisco: Jossey-Bass, Inc., 1979.

Larsen, J. (ed.), "Rediscovering Recovery," Innovations, I (1), Palo Alto: American Institutes for Research, 1980.

Levy, L., "Self-Help Groups: Types and Psychological Processes," Journal of Applied Behavioral Science, 12, 1976, pp. 310-322. Levy, L., "Self-Help Groups Viewed by Mental Health Professionals: A Survey and Comments," American Journal of Community Psychology, 6 (4), August 1978 .

Lieberman, M., and Borman, L., "Self-Help and Social Research," The Journal of Applied Behavioral Science, 12, 1976, pp. 455-463.

Long, N., et al, "Information and Referral Centers: A Functional Analysis," Inter-Study, Washington D.C.: DHEW, 1971. 


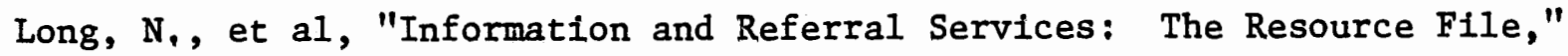
Inter-Study, MInneapolis: DHEW, 1973.

Mendel, w., Schizophrenia: The Experience and Its Treatment, San Francisco: Jossey-Bass, Inc, 1976.

Mendenhall, W., Ott, L., and Scheafer, R., Elementary Survey Sampling, Belmont, Ca.: Duxbury Press, 1971.

Morris, E., "Parents Without Partners, Inc,: A Resource for Clients," Social Work, April 1966.

Norton, G., and Corcoran, G., Techniques for Resource Identification and Service Inventory in Social Services Planning, Atlanta: The Research Group, 1976.

National Standards for Information and Referral Services, Phoenix:

Alliance of Information and Referral Services, Inc. (AIRS), 1978. NIMH, A Manual on State Mental Health Planning, Arthur D. Little, Inc. Maryland: DHEW Publication No. (ADM) 77-473, 1977.

NIMH, A Working Manual of Simple Program Evaluation Techniques for Community Mental Health Centers, Arthur D. Little, Inc., Maryland: DHEW Publication No, (ADM) 79-404, 1979.

NIMH, The Staff College, Washington, D.C.: 1979.

Omark, B., "The Dilemma of Membership in Recovery, Inc., A Self-Help

Ex-Mental Patient's Organization," Psychological Reports, 44 (3), 1979.

Oregon Legislative Assembly, House Bill 3132, June 18, 1979. Powell, T., "The Use of Self-Help Groups as Supportive Reference Communities," American Journal of Orthopsychiatry, 45(5), October 1975. 
Sheldon, D., "Self-Help in Mental Health? Impressions of Recovery, Incorporated," Journal of the Maine Medical Association; 69 (7) 1978, pp. 193-194.

Silverman, P., Mutual Help Groups: A Guide to Mental Health Professionals, Rockville, Md: NIMH, 1978.

Silverman, P., Mutual Help Groups: Organization and Development, Beverly

Hills: Sage Publications, 1978,

Spiegel, D., "The Psychiatrist as a Consultant to Self-Help Groups,"

Hospital and Community Psychiatry, 28, 1977, pp. 771-772.

Stein, L., (ed.), "Community Support Systems for the Long Term Patient," New Directions for Mental Health Services, New York: Jossey-Bass, 1970.

Stein, L., and Test, M., "Special Living Arrangements: A Model for

Decision-Making," Hospital and Community Psychiatry, 28 (8), August 1977, pp.608-610.

Suchman, E., Evaluation Research, New York: Russel Sage Foundation, 1967. Tessair, D., et al, "Information-Giving and Referral, Inter-Study, Washington, D.C.: DHEW, 1974.

Thompson, E., The Making of the English Working Class, London: Victor Gollanca, Ltd., 1963.

Tracy, G., and Gussow, Z., "Self-Help Groups: A Grassroots Response to a Need for Services," Journal of Applied Behavioral Science, 12 (3), 1976, pp. 381-396.

U. S. Government Printing Office, Report to the President's Commission on Mental Health, Washington, D.C.: Author, 1978. 
Wechsler, H,, "The Ex-patient Organization: A Survey," The Journal of Social Issues, 16, 1960a, pp. 47-53.

Weiss, C., Evaluation Research, New Jersey: Prentice-Hall, Inc., 1972. Wollert, R., et al, Make Today Count: A Collaborative Model for Professionals and Self-Help Groups," Professional Psychology, February 1980.

Worthen, B, and Sanders, S, (ed,), Educational Evaluation: Theory and Practice, Worthington, Ohio: Charles A, Jones Publishing Co., 1973.

Zimmerman, S., "I \& R Services; A Manifestation of and Response to Post Industrial Society," Information and Referral, I (3), 1979. 